\title{
Application of Quality-by-Design Approach in the Analytical Method Development for Quantification of Sugars in Sugarcane Honey by Reversed-Phase Liquid Chromatography
}

\author{
Pedro Silva ${ }^{1}$ (D) Catarina L. Silva ${ }^{1}$ (I) $\cdot$ Rosa Perestrelo $^{1}$ (D) $\cdot$ Fernando M. Nunes ${ }^{2}$ (D) $\cdot$ José S. Câmara $^{1,3}$ (D)
}

Received: 21 January 2020 / Accepted: 3 May 2020 / Published online: 30 May 2020

(C) Springer Science+Business Media, LLC, part of Springer Nature 2020

\begin{abstract}
Produced in Madeira Island from regional sugarcane cultivars through a traditional manufacturing and storage process, sugarcane honey $(\mathrm{SCH})$ is a black syrup recognized by its excellent quality. Its economic value has led to the emergence of adulterated $\mathrm{SCH}$, whereby the identification of molecular markers became an essential task in order to overcome the fraudulent activities, protect its authenticity, and guarantee the consumer safety. In the present study, an analytical strategy based on ultrasound-assisted liquidliquid extraction (USA-LLE) followed by reversed-phase liquid chromatography with a refractive index detector (LC-RI) was developed for the determination of sugars (glucose, fructose, sucrose, xylose, and mannose) in SCH samples from certified producers, supported on analytical quality-by-design (AQbD) approach, as a useful tool to establish its typicality. The application of AQbD was based on analytical risk assessment, multivariate statistics and quality control procedures for definition of the Method Operable Design Region (MODR). The optimal conditions into MODR were accomplished using BEH Amide column operating at a temperature of $80^{\circ} \mathrm{C}$ and a flow rate of $300 \mu \mathrm{L} \mathrm{min}{ }^{-1}$, with a mobile phase composed by acetone and water $(85: 15$, $v v^{-1}$ ) at a flow rate of $1.0 \mathrm{~mL} \mathrm{m^{-1 }}$. The robustness was determined by Monte Carlo simulation and capability analysis. The concentration-response function for all sugars was described by polynomial models. Accuracy was presented by recovery values between 98.2 and $119.5 \%$. The analytical figures of merit validated the utility of AQbD in the systematic design of a LC-RI method with fine sensitivity for sugar analysis in $\mathrm{SCH}$.
\end{abstract}

Keywords Sugarcane honey · Sugar · Typicality · Quality-by-design · USA-LLE · LC-RI

\section{Introduction}

Food authenticity has become a global problem, increasing the importance of the establishment of typicality markers to guarantee the authenticity of products and consumer safety.

Electronic supplementary material The online version of this article (https://doi.org/10.1007/s12161-020-01767-7) contains supplementary material, which is available to authorized users.

José S. Câmara

jsc@staff.uma.pt

1 CQM - Centro de Química da Madeira, Universidade da Madeira, Campus da Penteada, 9020-105 Funchal, Portugal

2 CQ-VR, Centro de Química - Vila Real, Departamento de Química, Universidade de Trás-os-Montes e Alto Douro, 5001-801 Vila Real, Portugal

3 Departamento de Química, Faculdade de Ciências Exatas e Engenharia, Universidade da Madeira; Campus da Penteada, 9020-105 Funchal, Portugal
The sugarcane honey ( $\mathrm{SCH}$ ), known as "mel-de-cana," is a black syrup produced in Madeira Island, Portugal, commonly used as a main ingredient in regional pastry and confectionery, being also consumed fresh and in traditional sauces for meat, fish and salads (Silva et al. 2017a; Silva et al. 2018). The manufacturing process of $\mathrm{SCH}$ was developed for more than a century, which started in late years of XIX century, since then, it has become a part of the historical and cultural patrimony of the region. This manufacturing process is based only in thermal treatment and filtering procedures of juice obtained by mechanical pressing of fresh stalks from regional sugarcane (Saccharum officinarum L.) cultivars, originating the worldwide recognized quality and unique organoleptic properties of SCH (Silva et al. 2017b). However, recently some low-quality products have been introduced in the market labeled as $\mathrm{SCH}$ that not respect the traditional manufacturing process or the use of regional cultivars. Many of these lowquality products are obtained as by-products from the sugar refining, alcoholic beverages and biofuel production industries, where refined sugars, corn syrups, invert syrups, or other 
low-cost syrups are also often added to reduce production costs (Silva et al. 2017a; Silva et al. 2018). These cases of product adulteration are threatening significantly the notoriety of SCH. Thus, it is imperative to develop strategies for establishment of typicality of SCH to guarantee its authenticity.

Sugars are the most abundant compounds found in nature, being widely used as molecular markers in food analysis domain for determination of geographical origin (Nikolaou et al. 2017; Coelho et al. 2018; Karabagias 2019), typicity (Ghfar et al. 2015; Mellado-Mojica et al. 2016; Kek et al. 2017) and authenticity (Cordella et al. 2005; Willems and Low 2012; Wang et al. 2015) of several food products. The sugar profile influences strongly the nutritional, sensory, and organoleptic properties of the final product, such as sweetness, viscosity, crystallization, granulation, and energy value (Özbalci et al. 2013; Georgelis et al. 2018). Moreover, several important active aroma and taste compounds are formed by thermal degradation (e.g., Maillard reactions, Strecker degradation, caramelization) and microbial activity (e.g., bacterial, yeast activity) on sugars during manufacturing and storage processes (Silva et al. 2017b; Georgelis et al. 2018). Although sucrose, glucose, and fructose are normally the main components of thermal processed sugary-products, such as agave syrup (Willems and Low 2012; Muñiz-Márquez et al. 2015), yacon syrup (de FG da Silva et al. 2018), date syrup (Al Eid 2006), maple syrup (Mellado-Mojica et al. 2016), raspberry syrup (Grembecka et al. 2014), beet molasse (Vaccari et al. 2001), cane honey (Seguí et al. 2015), sugarcane molasse (Xu et al. 2015), and inverted sugar syrup (Cordella et al. 2005), its profile varies depending on raw materials, manufacturing process, and storage. In this context, the establishment of sugars profile of SCH from certified producers can be a valuable strategy to define its typicality.

Recently, a wide variety of analytical methods have been proposed for sugars analysis of food products, synthesized in Table 1. Although some alternative analytical methods have been developed for the sugars analysis, such as gas chromatography (GC) coupled to mass spectrometry (MS) (Rodríguez-Sánchez et al. 2011; Guadalupe et al. 2012) or flame ionization detector (FID) (Willems and Low 2012; Idda et al. 2016), nuclear magnetic resonance (NMR) (Jamróz et al. 2014b), high performance thin layer chromatography (HPTLC) (Vaccari et al. 2001; Terol et al. 2010), capillary zone electrophoresis (CZE) (Rovio et al. 2011; Wang et al. 2012) and Raman spectroscopy (Özbalci et al. 2013). High performance anion exchange liquid chromatography with pulsed amperometry detection (HPAEC-PAD) (Cordella et al. 2005; Anjos et al. 2015; Seguí et al. 2015; Mellado-Mojica et al. 2016) and high performance liquid chromatography (HPLC) combined with refractive index detection (RI) (Al Eid 2006; Xu et al. 2015; Muñiz-Márquez et al. 2015; de FG da Silva et al. 2018) or evaporating light scattering detection (ELSD) (Ma et al. 2014; Kek et al. 2017;
Lindqvist et al. 2018) are the most widely applied methods for sugar profile of food products. Other types of detection are also used in combination with HPLC, namely mass spectrometry (MS) (Ghfar et al. 2015; Georgelis et al. 2018), fluorescence (FLD) (Rakete and Glomb 2013), ultraviolet (UV) (Bai et al. 2015), and charged aerosol detection (CAD) (Grembecka et al. 2014). However, FLD and UV detections require a time-consuming derivatization step before analysis, while MS and CAD detectors are too expensive for routine analysis (Ni et al. 2016; Koh et al. 2018). Although the HPAEC has been successfully applied to sugar profiling of some food products, the high-pH eluents that are required can generate interferents by epimerization or degradation of food components. In addition, poor resolution of sucrose is normally obtained in HPAEC-PAD analysis (Rakete and Glomb 2013; Koh et al. 2018). On the other hand, HPLC-ELSD and HPLC-IR are two popular methods for determination of underivatized sugars analysis without the use of high-pH eluents. However, HPLC-ELSD requires high amount of expensive nebulizer gas and presents low reproducibility and sensitivity in analysis of low molecular weight sugars (Ma et al. 2014; Magwaza and Opara 2015). Alternatively, HPLC-IR is a simple, fast and economical method that does not require additional gas or complex eluent gradient, being successfully used to sugar profiling of various food products, such as milk (Chávez-servín et al. 2004), juice (Nikolaou et al. 2017), wine (Coelho et al. 2018), fruits (Cantín et al. 2009; Filip et al. 2016), honey (Wang et al. 2015; Karabagias 2019), syrups (Al Eid 2006; Muñiz-Márquez et al. 2015; de FG da Silva et al. 2018), molasses (Xu et al. 2015), among others.

The lack of harmonization and quality processes in development of these analytical methods for sugar profiling hampers its application as a routine and precise tool in determination of typicity of food products. For example, during the development of most methods described in Table 1, an optimization of the parameters that affect its performance is not performed, and when performed, is based on the univariate strategy. Likewise, usually an appropriate method validation procedure is not applicated. Thus, the applicability of analytical information obtained by these described methods in other food products is complicated, being imperative the implementation of quality and harmonized procedures in development of analytical methods.

Analytical quality-by-design (AQbD) is an effective and successful approach for quality assurance in the development of an analytical method based on risk assessment, multivariate statistics, and control quality procedures, being recognized by European Medicines Agency (EMA) and Food and Drug Administration (FDA) regulators as a performance qualifier of analytical methods (EMA and FDA 2013; Silva et al. 2017b). The International Conference on Harmonization (ICH) in Guideline ICHQ8(R2) (ICH 2009) define AQbD as "a systematic approach to development that begins with 
Table 1 Analytical methods for determination of sugars in food matrices

\begin{tabular}{|c|c|c|c|c|c|c|c|}
\hline Sugars & Food product & $\begin{array}{l}\text { Study } \\
\text { propose }\end{array}$ & $\begin{array}{l}\text { Sample } \\
\text { preparation }\end{array}$ & Analysis & Optimization type & $\begin{array}{l}\text { Validation } \\
\text { parameters }\end{array}$ & Reference \\
\hline $\begin{array}{l}\text { Fructose, glucose, galactose, } \\
\text { sucrose, lactulose, lactose }\end{array}$ & Milk & Sugar profile & LLE & LC-RI & n.p. ${ }^{a}$ & $\begin{array}{l}\text { Linearity, } \\
\text { accuracy, } \\
\text { precision, } \\
\text { LOD, } \\
\text { LOQ }\end{array}$ & $\begin{array}{l}\text { (Chávez-Servín et al. } \\
\text { 2004) }\end{array}$ \\
\hline $\begin{array}{l}\text { Fructose, glucose; sucrose, } \\
\text { sorbitol }\end{array}$ & $\begin{array}{l}\text { Peach, } \\
\text { nectarine }\end{array}$ & Cultivars & LLE & LC-RI & n.p. ${ }^{\text {a }}$ & n.p. ${ }^{\text {a }}$ & (Cantín et al. 2009) \\
\hline $\begin{array}{l}\text { Fructose, glucose; sucrose, } \\
\text { sorbitol }\end{array}$ & Apple & Cultivars & UA-LLE & LC-RI & $\begin{array}{l}\text { Box-Behnken } \\
\text { design } \\
\text { (H2SO4 } \\
\text { concentration, } \\
\text { flow rate, } \\
\text { column } \\
\text { temperature) }\end{array}$ & $\begin{array}{l}\text { Linearity, } \\
\text { accuracy, } \\
\text { precision, } \\
\text { LOD, } \\
\text { LOQ }\end{array}$ & (Filip et al. 2016) \\
\hline Fructose, glucose & Orange juice & $\begin{array}{l}\text { Geographical } \\
\text { origin }\end{array}$ & n.p. ${ }^{\mathrm{a}}$ & LC-RI & n.p. ${ }^{\text {a }}$ & $\begin{array}{l}\text { Linearity, } \\
\text { accuracy, } \\
\text { precision, } \\
\text { LOD, } \\
\text { LOQ }\end{array}$ & $\begin{array}{l}\text { (Nikolaou et al. } \\
\text { 2017) }\end{array}$ \\
\hline $\begin{array}{l}\text { Maltose, glucose, fructose, } \\
\text { rhamnose }\end{array}$ & $\begin{array}{l}\text { Grape juice, } \\
\text { wine }\end{array}$ & $\begin{array}{l}\text { Geographical } \\
\text { origin }\end{array}$ & n.p. ${ }^{a}$ & LC-RI & n.p. ${ }^{\mathrm{a}}$ & $\begin{array}{l}\text { Linearity, } \\
\text { accuracy, } \\
\text { precision, } \\
\text { LOD, } \\
\text { LOQ }\end{array}$ & (Coelho et al. 2018) \\
\hline $\begin{array}{l}\text { Fructose, glucose, sucrose, } \\
\text { maltose }\end{array}$ & Honey & $\begin{array}{l}\text { Geographical } \\
\text { origin }\end{array}$ & LLE & LC-RI & n.p. ${ }^{\mathrm{a}}$ & $\begin{array}{l}\text { Linearity, } \\
\text { precision, } \\
\text { LOD, } \\
\text { LOQ }\end{array}$ & (Karabagias 2019) \\
\hline $\begin{array}{l}\text { Fructose, glucose, sucrose, } \\
\text { maltose, maltotriose, } \\
\text { maltotetraose, } \\
\text { maltopentaose, } \\
\text { maltohexaose, } \\
\text { maltoheptaose }\end{array}$ & Honey & Adulteration & n.p. ${ }^{a}$ & LC-RI & n.p. ${ }^{\mathrm{a}}$ & n.p. ${ }^{1}$ & (Wang et al. 2015) \\
\hline Fructose, glucose, sucrose & $\begin{array}{l}\text { Sugarcane } \\
\text { molasses }\end{array}$ & Sugar profile & SPE Clean-up & LC-RI & $\begin{array}{l}\text { Univariate design } \\
\text { (column type, } \\
\text { mobile phase) }\end{array}$ & $\begin{array}{l}\text { Linearity, } \\
\text { accuracy, } \\
\text { precision, } \\
\text { LOD }\end{array}$ & (Xu et al. 2015) \\
\hline $\begin{array}{l}\text { Fructose, glucose; sucrose; } \\
\text { kestose }\end{array}$ & Agave syrup & Sugar profile & n.p. ${ }^{\mathrm{a}}$ & LC-RI & n.p. ${ }^{\mathrm{a}}$ & n.p. ${ }^{a}$ & $\begin{array}{l}\text { (Muñiz-Márquez } \\
\text { et al. 2015) }\end{array}$ \\
\hline $\begin{array}{l}\text { Fructose, glucose, sucrose, } \\
\text { maltose }\end{array}$ & Yacon syrup & Sugar profile & LLME & LC-RI & n.p. ${ }^{a}$ & n.p. ${ }^{a}$ & $\begin{array}{l}\text { (de FG da Silva et al. } \\
\text { 2018) }\end{array}$ \\
\hline Fructose, glucose, sucrose & Date syrup & Sugar profile & n.p. ${ }^{a}$ & LC-RI & n.p. ${ }^{a}$ & n.p. ${ }^{a}$ & (Al Eid 2006) \\
\hline Fructose, glucose, sucrose & Nectar & Sugar profile & n.p. ${ }^{a}$ & LC-ELSD & n.p. ${ }^{\mathrm{a}}$ & $\begin{array}{l}\text { Linearity, } \\
\text { Accurac- } \\
\text { y, } \\
\text { Precision, } \\
\text { LOD, } \\
\text { LOQ }\end{array}$ & $\begin{array}{l}\text { (Lindqvist et al. } \\
\text { 2018) }\end{array}$ \\
\hline $\begin{array}{l}\text { Fructose, glucose; sucrose, } \\
\text { sorbitol }\end{array}$ & $\begin{array}{l}\text { Peach, apple, } \\
\text { watermelon, } \\
\text { cherry fruits }\end{array}$ & Sugar profile & n.p. ${ }^{a}$ & LC-ELSD & $\begin{array}{l}\text { Univariate design } \\
\text { (column } \\
\text { temperature, } \\
\text { mobile phase, } \\
\text { gas flow rate) }\end{array}$ & $\begin{array}{l}\text { Linearity, } \\
\text { accuracy, } \\
\text { precision, } \\
\text { LOD, } \\
\text { LOQ }\end{array}$ & (Ma et al. 2014) \\
\hline Fructose, glucose, sucrose & Honey & Typicality & n.p. ${ }^{\mathrm{a}}$ & LC-ELSD & n.p. ${ }^{a}$ & n.p. ${ }^{a}$ & (Kek et al. 2017) \\
\hline $\begin{array}{l}\text { Fructose, glucose, sucrose, } \\
\text { maltose, lactose, } \\
\text { erythritol, xylitol, } \\
\text { sorbitol, mannitol, }\end{array}$ & $\begin{array}{l}\text { Candies, gum, } \\
\text { jelly, } \\
\text { chocolate }\end{array}$ & Sugar profile & LLE & UPLC-ELSD & $\begin{array}{l}\text { Univariate design } \\
\text { (column type, } \\
\text { mobile phase) }\end{array}$ & $\begin{array}{l}\text { Linearity, } \\
\text { accuracy, } \\
\text { LOD, } \\
\text { LOQ }\end{array}$ & (Koh et al. 2018) \\
\hline
\end{tabular}


Table 1 (continued)

\begin{tabular}{|c|c|c|c|c|c|c|c|}
\hline Sugars & Food product & $\begin{array}{l}\text { Study } \\
\text { propose }\end{array}$ & $\begin{array}{l}\text { Sample } \\
\text { preparation }\end{array}$ & Analysis & Optimization type & $\begin{array}{l}\text { Validation } \\
\text { parameters }\end{array}$ & Reference \\
\hline \multicolumn{8}{|l|}{$\begin{array}{l}\text { inositol, maltitol, lactitol, } \\
\text { isomalt }\end{array}$} \\
\hline $\begin{array}{l}\text { Fructose, glucose; sucrose, } \\
\text { maltose, maltotriose }\end{array}$ & $\begin{array}{l}\text { Honey, } \\
\quad \text { inverted } \\
\text { sugar syrup }\end{array}$ & Adulteration & n.p. ${ }^{a}$ & HPAEC-PAD & n.p. ${ }^{\mathrm{a}}$ & n.p. ${ }^{\mathrm{a}}$ & $\begin{array}{l}\text { (Cordella et al. } \\
\text { 2005) }\end{array}$ \\
\hline $\begin{array}{l}\text { Trehalose, glucose, fructose, } \\
\text { sucrose, melezitose, } \\
\text { turanose, maltose }\end{array}$ & Honey & Sugar profile & n.p. ${ }^{a}$ & HPAEC-PAD & n.p. ${ }^{a}$ & LOQ & (Anjos et al. 2015) \\
\hline Fructose, glucose, sucrose & $\begin{array}{l}\text { Cane honey, } \\
\text { jaggeries, } \\
\text { brown sugar }\end{array}$ & Sugar profile & n.p. ${ }^{a}$ & HPAEC-PAD & n.p. ${ }^{\mathrm{a}}$ & n.p. ${ }^{\mathrm{a}}$ & (Seguí et al. 2015) \\
\hline Fructose, glucose, sucrose & Maple syrup & Typicality & n.p. ${ }^{a}$ & HPAEC-PAD & n.p. ${ }^{a}$ & n.p. ${ }^{a}$ & $\begin{array}{l}\text { (Mellado-Mojica } \\
\text { et al. 2016) }\end{array}$ \\
\hline $\begin{array}{l}\text { Rhamnose, fructose, } \\
\text { glucose,sucrose, lactose, } \\
\text { raffinose, maltose, erlose }\end{array}$ & $\begin{array}{l}\text { Honeydew, } \\
\text { nectar }\end{array}$ & Sugar profile & UA-LLE & HPAEC-PAD & $\begin{array}{l}\text { Univariate design } \\
\text { (column type, } \\
\text { mobile phase, } \\
\text { sample } \\
\text { elimination) }\end{array}$ & $\begin{array}{l}\text { Linearity, } \\
\text { LOD, } \\
\text { LOQ }\end{array}$ & (Ni et al. 2016) \\
\hline Fructose, glucose, sucrose & $\begin{array}{l}\text { Potato, } \\
\text { strawberry }\end{array}$ & Typicality & LLE & LC-MS & $\begin{array}{l}\text { Univariate design } \\
\text { (extraction } \\
\text { method) }\end{array}$ & $\begin{array}{l}\text { Selectivity, } \\
\text { linearity, } \\
\text { accuracy, } \\
\text { precision, } \\
\text { LOD, } \\
\text { LOQ }\end{array}$ & $\begin{array}{l}\text { (Georgelis et al. } \\
\text { 2018) }\end{array}$ \\
\hline $\begin{array}{l}\text { Fructose, glucose,sucrose, } \\
\text { kestose, nystose }\end{array}$ & Palm fruit dates & Sugar profile & LLE & UPLC-MS & $\begin{array}{l}\text { Univariate design } \\
\text { (column type, } \\
\text { mobile phase) }\end{array}$ & $\begin{array}{l}\text { Linearity, } \\
\text { accuracy, } \\
\text { precision, } \\
\text { LOD, } \\
\text { LOQ }\end{array}$ & (Ghfar et al. 2015) \\
\hline $\begin{array}{l}\text { Glucose, fructose, sucrose, } \\
\text { maltose, erythritol, } \\
\text { mannitol, maltitol, } \\
\text { sorbitol, xylitol }\end{array}$ & $\begin{array}{l}\text { Orange-apple } \\
\text { juices, black } \\
\text { currant- } \\
\text { cherry } \\
\text { nectars, } \\
\text { raspberry } \\
\text { syrup }\end{array}$ & Sugar profile & n.p. ${ }^{a}$ & LC-CAD & $\begin{array}{l}\text { Univariate design } \\
\text { (column } \\
\text { temperature, } \\
\text { mobile phase, } \\
\text { column flow } \\
\text { rate) }\end{array}$ & $\begin{array}{l}\text { Linearity, } \\
\text { accuracy, } \\
\text { precision, } \\
\text { LOD, } \\
\text { LOQ }\end{array}$ & $\begin{array}{l}\text { (Grembecka et al. } \\
\text { 2014) }\end{array}$ \\
\hline $\begin{array}{l}\text { Ribose, xylose, glucose, } \\
\text { maltose, isomaltose, } \\
\text { maltotriose, } \\
\text { maltopentaose, } \\
\text { maltohexaose, } \\
\text { maltoheptaose }\end{array}$ & Beer & Sugar profile & Derivatization & $\begin{array}{l}\text { LC-FLD, } \\
\text { LC-MS }\end{array}$ & n.p. ${ }^{a}$ & n.p. ${ }^{a}$ & $\begin{array}{l}\text { (Rakete and Glomb } \\
\text { 2013) }\end{array}$ \\
\hline $\begin{array}{l}\text { Isomaltose, isomaltotriose, } \\
\text { panose, maltose, glucose }\end{array}$ & Wine rice & Sugar profile & Derivatization & LC-UV & n.p. ${ }^{a}$ & $\begin{array}{l}\text { Linearity, } \\
\text { accuracy, } \\
\text { precision, } \\
\text { LOD, } \\
\text { LOQ }\end{array}$ & (Bai et al. 2015) \\
\hline $\begin{array}{l}\text { Maltoheptose, maltohexose, } \\
\text { maltopentose, } \\
\text { maltotetrose maltotriose, } \\
\text { maltose, sucrose, glucose, } \\
\text { fructose, xylose, } \\
\text { rhamnose }\end{array}$ & Beet molasses & Sugar profile & Derivatization & HPTLC-FLD & n.p. ${ }^{a}$ & n.p. ${ }^{a}$ & (Vaccari et al. 2001) \\
\hline $\begin{array}{l}\text { Ribose, glucose, fructose, } \\
\text { galactose, inositol, } \\
\text { galactinol }\end{array}$ & Mulberry & Sugar profile & $\begin{array}{l}\text { LLE, } \\
\text { derivatiza- } \\
\text { tion }\end{array}$ & GC-MS & $\begin{array}{l}\text { Univariate design } \\
\text { (derivatization } \\
\text { procedure) }\end{array}$ & $\begin{array}{l}\text { Linearity, } \\
\text { accuracy, } \\
\text { precision, } \\
\text { LOD, } \\
\text { LOQ }\end{array}$ & $\begin{array}{l}\text { (Rodríguez-Sánchez } \\
\text { et al. 2011) }\end{array}$ \\
\hline $\begin{array}{l}\text { Apiose, arabinose, } \\
\text { rhamnose, fucose, xylose, }\end{array}$ & Wine & Sugar profile & Derivatization & $\begin{array}{l}\text { GC-MS, } \\
\text { GC-FID }\end{array}$ & n.p. ${ }^{a}$ & $\begin{array}{l}\text { Linearity, } \\
\text { accuracy, }\end{array}$ & $\begin{array}{l}\text { (Guadalupe et al. } \\
\text { 2012) }\end{array}$ \\
\hline
\end{tabular}


Table 1 (continued)

\begin{tabular}{|c|c|c|c|c|c|c|c|}
\hline Sugars & Food product & $\begin{array}{l}\text { Study } \\
\text { propose }\end{array}$ & $\begin{array}{l}\text { Sample } \\
\text { preparation }\end{array}$ & Analysis & Optimization type & $\begin{array}{l}\text { Validation } \\
\text { parameters }\end{array}$ & Reference \\
\hline $\begin{array}{l}\text { mannose, galactose, } \\
\text { glucose }\end{array}$ & & & & & & $\begin{array}{l}\text { precision, } \\
\text { LOD, } \\
\text { LOQ }\end{array}$ & \\
\hline $\begin{array}{l}\text { Glucose, lactose, galactose, } \\
\text { inositol }\end{array}$ & Milk & Sugar profile & Derivatization & GC-FID & $\begin{array}{l}\text { Univariate design } \\
\text { (injection } \\
\text { volume) }\end{array}$ & $\begin{array}{l}\text { Linearity, } \\
\text { accuracy, } \\
\text { precision, } \\
\text { LOD, } \\
\text { LOQ }\end{array}$ & (Idda et al. 2016) \\
\hline $\begin{array}{l}\text { Fructose, glucose, sucrose, } \\
\text { mannitol, inositol }\end{array}$ & Agave syrup & Authenticity & n.p. ${ }^{a}$ & $\begin{array}{l}\text { GC-FID, } \\
\text { HPAEC-P- } \\
\text { AD }\end{array}$ & n.p. ${ }^{\mathrm{a}}$ & n.p. ${ }^{\mathrm{a}}$ & $\begin{array}{l}\text { (Willems and Low } \\
\text { 2012) }\end{array}$ \\
\hline $\begin{array}{l}\text { Fructose, glucose, sucrose, } \\
\text { maltose }\end{array}$ & Honey & Sugar profile & n.p. ${ }^{\mathrm{a}}$ & $\begin{array}{l}\text { Raman } \\
\text { spectrosco- } \\
\text { py }\end{array}$ & n.p. ${ }^{a}$ & n.p. ${ }^{a}$ & (Özbalci et al. 2013) \\
\hline $\begin{array}{l}\text { Fructose, glucose, sucrose, } \\
\text { maltose }\end{array}$ & Honey & Sugar profile & n.p. ${ }^{a}$ & NMR & n.p. ${ }^{\mathrm{a}}$ & n.p. ${ }^{\mathrm{a}}$ & (Jamróz et al. 2014a) \\
\hline $\begin{array}{l}\text { Maltose, lactose, xylose, } \\
\text { arabinose, glucose, } \\
\text { ribose, rhamnose, fucose, } \\
\text { galactose, mannose }\end{array}$ & Beer, milk & Sugar profile & $\begin{array}{l}\text { LLE, } \\
\text { Derivatiza- } \\
\text { tion }\end{array}$ & CZE-UV & n.p. ${ }^{\mathrm{a}}$ & $\begin{array}{l}\text { Linearity, } \\
\text { accuracy, } \\
\text { precision, } \\
\text { LOD, } \\
\text { LOQ }\end{array}$ & (Wang et al. 2012) \\
\hline $\begin{array}{l}\text { Cellobiose, fructose, fucose, } \\
\text { galactose, glucose, } \\
\text { inositol, mannitol, } \\
\text { mannose, rhamnose, } \\
\text { ribose, sorbitol, trehalose, } \\
\text { xylose }\end{array}$ & Wine & $\begin{array}{l}\text { Geographical } \\
\text { origin }\end{array}$ & n.p. ${ }^{\mathrm{a}}$ & CZE-UV & n.p. ${ }^{a}$ & $\begin{array}{l}\text { Linearity, } \\
\text { accuracy, } \\
\text { precision, } \\
\text { LOD, } \\
\text { LOQ }\end{array}$ & (Rovio et al. 2011) \\
\hline
\end{tabular}

$L O D$ limit of detection, $L O Q$ limit of quantification, $L L E$ liquid-liquid extraction, $C Z E-U V$ capillary zone electrophoresis-ultraviolet, $N M R$ nuclear magnetic resonance, $G C-F I D$ gas chromatography-flame ionization detection, $H P A E C-P A D$ high performance anion exchange liquid chromatography with pulsed amperometry detection, GC-MS gas chromatography-mass spectrometry, HPTLC-ICP-AES high performance thin layer chromatography, $H P T L C$-FLD high performance thin layer chromatography-fluorescence detector, HPTLC-UV high performance thin layer chromatography-ultraviolet, $H P L C-M S$ high performance liquid chromatography-mass spectrometry, HPLC-CAD high performance liquid chromatography-charged aerosol detection, $U P L C-M S$ ultra performance liquid chromatography-mass spectrometry, $L C$-ELSD - high performance liquid chromatography-evaporating light scattering detection, UPLC-ELSD - ultra performance liquid chromatography-evaporating light scattering detection, $L C$ - $R I$ - high performance liquid chromatography-refractive index detection, USA-LLE ultrasound-assisted liquid-liquid extraction, SPE solid phase extraction

${ }^{\text {a }}$ Not performed in study

predefined objectives and emphasizes product and process understanding and process control, based on sound science and quality risk management." Normally, the workflow of $\mathrm{AQbD}$ for development of an analytical method is based on the follow key stages: (i) selection of analytical target profile (ATP), where the analytes, extraction technique, and analysis equipment are selected according the purpose of study; (ii) definition of critical method attributes (CMAs), which are representative of the analytical performance of method, such as peak area, peak resolution, peak asymmetry and retention time; (iii) method scouting through preliminary studies, where are evaluated which parameters have the potential to influence the CMAs; (iv) selection of parameters by quality risk assessment (QRA) based on the Ishikawa diagram according scouting phase results; (v) determination of critical method parameters (CMPs), where the parameters that significantly affect the analytical performance of method are defined; (vi) definition of knowledge space (KS) by design of experiments screening to explore the effects of the CMPs on the CMAs; (vii) definition of method operable design region (MODR) through statistical analysis of method responses based on the interactions between the CMPs and CMAs, such as Pareto analysis, response surface methodology and desirability analysis; (viii) evaluation of method robustness by its capacity to remain unaffected by small deliberate variations on the MODR; (ix) method control by establishment of system suitability limits on the MODR; ( $\mathrm{x}$ ) validation of method by determination of selectivity, calibration function, linearity, precision, accuracy, matrix effect, limits of detection (LOD) and quantitation (LOQ); (xi) applicability of method to real samples (Borman et al. 2007; Hanna-Brown et al. 2010; Molnár et al. 2010; Silva et al. 2017b; Ancillotti et al. 2018). Although the AQbD approach has been widely applied in the pharmaceutical industry, only in last years has started to be introduced 
in food analysis. The first application of AQbD approach in development of an analytical method for food analysis was described in our previously study, where AQbD procedures was applied for identification and quantification of furan derivatives in authenticity of SCH samples (Silva et al. 2017b; Silva et al. 2018). Recently, other two studies were published, where the analytical methods were developed based on AQbD framework for determination of polyphenols in diospyros fruit (Ancillotti et al. 2018) and cereals (Balli et al. 2020). The application of AQbD principles is a promising strategy to improve the confidence, control and harmonization of analytical methods and facilitate the exchange of analytical information in food analysis.

The objective of the present study was to develop a robust and precise strategy based on ultrasound-assisted liquid-liquid extraction (USA-LLE) combined with reversed phase LC-RI, employing AQbD approach, for quantification of sugars (glucose, fructose, sucrose, xylose, and mannose) in $\mathrm{SCH}$ samples from a certified producer during three consecutive production years (2016, 2017 and 2018), as a powerful strategy to define its typicality.

\section{Materials and Methods}

\section{Samples, Standards, Reagents, and Materials}

SCH samples were provided by the certified producer Fábrica de Mel-de Cana do Ribeiro Sêco in April 2016 (FRS16), 2017 (FRS17), and 2018 (FRS18) (Madeira Island, Portugal), and stored under stable conditions $\left(4^{\circ} \mathrm{C}\right.$, in the dark). Sugars standards, glucose (GLU), fructose (FRU), sucrose (SUC), xylose (XYL), mannose (MAN), and rhamnose (RHA) were purchased from Sigma-Aldrich (St. Louis, USA). Acetone $(\mathrm{ACT})$, acetonitrile $(\mathrm{ACN})$, ethanol $(\mathrm{EtOH})$, methanol $(\mathrm{MeOH})$, and triethylamine (TEA) were purchased from Sigma-Aldrich (St. Louis, USA). Ultrapure deionized water $\left(\mathrm{H}_{2} \mathrm{O}\right)$, purified with a Milli-Q ultra-pure water system from Millipore (Massachusetts, USA). All solvents and samples were filtered through $0.22 \mu \mathrm{m}$ membrane filters from Millipore (Massachusetts, USA), before analysis.

\section{Sugar Standard Solution Preparation}

Sugar standard stock solutions $\left(100 \mathrm{~g} \mathrm{~L}^{-1}\right)$ were prepared by $500 \mathrm{mg}$ of each standard in $5 \mathrm{~mL} \mathrm{H}_{2} \mathrm{O}: \mathrm{EtOH}$ (50:50\%, $v v^{-1}$ ), and stored at $-20{ }^{\circ} \mathrm{C}$. Under these conditions, the standards solutions are stable for at least 3 months. Working solutions of lower concentrations with all sugars standards were daily prepared by appropriate dilution with $\mathrm{H}_{2} \mathrm{O}$ :ACT $\left(50: 50 \%, v v^{-1}\right)$.

\section{USA-LLE}

USA-LLE procedure was performed adding $2.5 \mathrm{~g} \mathrm{SCH}$ and $7.5 \mathrm{~mL} \mathrm{H}_{2} \mathrm{O}$ :ACT $\left(50: 50 \%, v v^{-1}\right)$ into a $50 \mathrm{~mL}$ PTFE centrifuge tube, followed by homogenization (MAXI MIX Vortex Mixer, from Thermo Scientific, MA, USA) for 2 min and ultrasonication (BRANSON 2510 ultrasonic cleaner, from Bransonic, CT, USA) for 10 min. After this, the extraction solution was centrifuged (ROTOFIX 32A, from Hettich, Kirchlengern, Germany) at $4000 \mathrm{rpm}$ for $15 \mathrm{~min}$. A 2-mL aliquot from the upper part of the extraction solution (ACT phase) was transferred into an 8-mL glass flask. Before injection into the HPLC-RI system, all extracts were filtered through $0.22-\mu \mathrm{m}$ membrane filters and transferred to HPLC vials.

\section{LC-RI Conditions}

The sugar analysis was performed on a HPLC ULTIMATE 3000 series system acquired from Dionex, CA, USA, equipped with a binary pump, an autosampler and a column compartment, coupled to a refractive index detector SHODEX R1-101 from Thermo Scientific, Massachusetts, USA. The instrument configuration and analysis were achieved with Chromeleon ${ }^{\mathrm{TM}}$ Chromatography Data System Software from Thermo Scientific, Massachusetts, USA. The chromatographic separation of sugars was carried on a X-Bridge BEH Amide $\mathrm{XP}(2.5 \mu \mathrm{m}, 4.6 \times 100 \mathrm{~mm})$ column acquired from Waters Corporation, MA, USA. The binary mobile phase was composed by $\mathrm{H}_{2} \mathrm{O}$ with $0.05 \%$ TEA (eluent $\mathrm{A}$ ) and ACT (eluent $\mathrm{B})$, with an isocratic gradient $(15 \% \mathrm{~A}$ and $85 \% \mathrm{~B})$ at a constant flow rate at $300 \mu \mathrm{L} \mathrm{min}{ }^{-1}$. The temperatures were strictly controlled, and the column was kept at $80^{\circ} \mathrm{C}$, sample manager at $20^{\circ} \mathrm{C}$ and IR flow cell at $50^{\circ} \mathrm{C}$. The injection volume was set at eight $\mu \mathrm{L}$. The sugars identification was based on the retention times (RTs) of sugar standards, being quantified by the standard calibration curves method.

\section{Statistical Software}

All data analysis and statistical processing were performed using the STATSOFT STATISTICA 12.0 (2013) software (Tulsa, USA).

\section{Results and Discussion}

The analytical method was developed according the AQbD approach, based on the procedure described in our previous study (Silva et al. 2017b), adapted from recommendations defined in ICHQ8(R2) (ICH 2009) guideline. The workflow chart for $\mathrm{AQbD}$ approach is described in Online Resource 1 (Supplementary Material). 


\section{ATP, Critical Quality Attributes, and Method Scouting}

The ATP of this study was defined by separation, identification, and quantification of GLU, FRU, SUC, XYL, and MAN in SCH samples from a certified producer during three consecutive production years $(2016,2017$, and 2018) through USA-LLE/LC-RI analytical method. FRU, GLU, and SUC were selected in this study because these are the most abundant sugars in sugarcane-based food products. In addition, these sugars are also present in widely used adulterants, being added individually or as ingredient of corn syrups, beet syrup, invert syrups, or other low-cost syrups (Başar and Özdemir 2018). Similarly, MAN (Hu et al. 2016) and XYL (Saska and Ozer 1995) were also selected for their potential use as alternative sugary adulterants.

The definition of CMAs was based on chromatography performance of the analytical method, where were selected the total peak area (TPA), peak resolution (PR), and peak asymmetry (PA) of each sugar standard, as well the respective relative standard deviation (RSD). The limits for CMAs values were established according the minimal requirements for a satisfactory chromatography performance, where was mandatory the identification of each sugar standard based on TPA and RT, PR values greater than 1.5, PA values lower than 1.5, and RSD values not higher than $15 \%$ (Thompson et al. 2002).

The method scouting was performed by several preliminary experiments. The extraction performance of analytical method was evaluated by comparison between LLE and USA-LLE, and other extraction-influencing parameters (data not shown). The results (TPA and RSD) obtained by USALLE were considerable superior than LLE. The use of ultrasound in the LLE possibly provides a better dispersion of the target sugars from samples to the extraction phase (ACT). However, no differences were observed between the different tested times $(10,20$, and $30 \mathrm{~min})$ of ultrasound. In addition, three different extraction solvents were evaluated, ACT, can, and $\mathrm{MeOH}$, being that only the extraction performed with ACT provided satisfactory results. The poor results obtained by $\mathrm{ACN}$ and $\mathrm{MeOH}$ may be due to the fact that the mobile phase used in the chromatographic analysis contains high content $(85 \%)$ of ACT. Also, different extraction solvent contents were studied $(50,60$, and $70 \%)$ and no differences were observed. Similarly, the ratios 1:1, 1:2, and 1:3 $\left(w v^{-1}\right)$ between sample and extraction solution $\left(\mathrm{H}_{2} \mathrm{O}\right.$ and $\left.\mathrm{ACT}\right)$ were evaluated. The ratio 1:3 was selected to avoid problems related with high viscosity of SCH samples. The scouting of chromatography performance was based on results from WATERS technology brief (Benvenuti and Burgess 2012), where the analysis of FRU, GLU, and SUC in several fruit juices was performed by LC-RI with a X-Bridge BEH Amide XP column and a binary mobile phase $\left(15 \% \mathrm{H}_{2} \mathrm{O}\right.$ with $0.05 \%$ TEA and $85 \%$ ACT) in isocratic gradient mode.

\section{QRA and CMPs}

The selection of CMPs was performed by QRA through an Ishikawa diagram constructed according the results obtained on method scouting step, being displayed in Online Resource 2. Although several extraction-influencing parameters have been studied, no CMPs were selected for USA-LLE. On previous scouting step, none of studied parameters demonstrated that its range variability can affect the extraction efficiency of the method. The previously investigated parameters for USALLE were kept during further steps of method development. On the other hand, the chromatography performance can be affected by variability of several parameters from LC-RI analysis. The selected CMPs were the type of eluent B, content (\%) of eluent B, column flow rate, and column temperature.

\section{Knowledge Space}

The WATERS technology brief (Benvenuti and Burgess 2012) provide an excellent source of valuable information for definition of influencing CMPs ranges and screening of KS. A full factorial design (FFD) based on $4^{3}$-level factors model was applied as design of experiments for KS screening, being investigated the eluent B (ACT, $\mathrm{ACN}$, and $\mathrm{MeOH})$, eluent $\mathrm{B}$ content $(75,80$, and $85 \%$ ), column flow rate $\left(300,400\right.$, and $\left.500 \mu \mathrm{L} \mathrm{min}{ }^{-1}\right)$, and column temperature $\left(60,70\right.$, and $\left.80^{\circ} \mathrm{C}\right)$. Unexpectedly, the mobile phases with $\mathrm{ACN}$ and $\mathrm{MeOH}$ did not allow the separation of sugars under analysis. Moreover, ACN and $\mathrm{MeOH}$ caused a co-elution of all compounds, making it impossible to identify the five sugars under analysis. Although the most studies published of sugar analysis based on LC-RI use only aqueous eluents (Wang et al. 2015; Coelho et al. 2018), organic eluents, such as ACN, already have been used successfully. For example, GLU, FRU, and SUC were separated and identified in molasses samples, utilizing an Utimate XB-NH2 column $(5 \mu \mathrm{m}$, $4.6 \times 250 \mathrm{~mm}$ ) with a binary mobile phase composed by $\mathrm{ACN}$ and $\mathrm{H}_{2} \mathrm{O}\left(75: 25 \%, v v^{-1}\right)$ (Xu et al. 2015). Other study also used a binary mobile phase composed by ACN and $\mathrm{H}_{2} \mathrm{O}\left(40: 60 \%, v v^{-1}\right)$ in a Zorbax RX-SIL column $(5 \mu \mathrm{m}, 4.6 \times 250 \mathrm{~mm})$ for analysis of GLU, FRU, and SUC in honey samples (Karabagias 2019). Possibly, in our study, the combination of the short length $(100 \mathrm{~mm})$ and amide groups of column promotes a rapid elution of sugars, not allowing them to separate with these two organic eluents, even using a low column flow rate $\left(300 \mu \mathrm{L} \mathrm{min}{ }^{-1}\right)$. For this reason, the FFD for KS screening was really based on $3^{3}$-level factors model. The CMAs (TPA, PR and PA) results, CMPs and respective range values of KS FFD screening model are summarized in Online Resource 3 to Online Resource 5, respectively. 


\section{Method Operable Design Region (MODR)}

The definition of MODR was based on LC analysis, wherein the CMA responses from the interactions of previous selected CMPs were evaluated through the $3^{3}$-level factors model FFD defined previously in KS. The optimum CMAs responses from interactions between CMPs were exhaustively explored through Pareto ranking analysis (PRA), response surface methodologies (RSM), and desirability analysis (DA) in order to define an MODR where the analytical method will achieve the purposed ATP. The MODR definition was achieved through the TPA, PR, and PA responses obtained from ACT content, column flow rate, and column temperature, and from its interactions. The PRA for TPA, PR, and PA are shown in Fig. $1 \mathrm{a}, \mathrm{b}$, and c, respectively.

According to results, all CMPs demonstrated, individually, a significant influence on the TPA response, being that its influence decreased in the following order: column flow rate $>$ ACT content $>$ column temperature. However, only the interaction between ACT content and column flow rate presented a significant influence on the TPA response. Likewise, all CMPs showed an individual and significant influence on the PR response, wherein its influence decreased according this order: ACT content $>$ column temperature $>$ column flow rate. The PR response was also significantly influenced by interaction between the ACT content with column flow rate and column temperature. Regarding the results from PA response, the ACT content and column temperature were the only CMPs with a significant effect. Thus, all CMPs confirmed its significant influence on CMAs responses, and consequently, in definition of MODR.

The RSM plots of interaction between the range level of continuous CMPs (ACT content vs column flow rate, ACT content vs column temperature, and column flow rate vs column temperature), on TPA, PR, and PA responses are presented in Fig. 2a-c, d-f, and g-i, respectively.

Based on results, it was verified that the higher TPA values were obtained by the content of $85 \%$ ACT with a column flow rate of $300 \mu \mathrm{L} \mathrm{min}^{-1}$ and a column temperature of $80^{\circ} \mathrm{C}$. The
ACT content below $85 \%$ and column flow rate above $300 \mu \mathrm{L} \min ^{-1}$ caused a clearly decrease in TPA values. On the other hand, only smooth differences were observed between the studied ranges of column temperature, where $80{ }^{\circ} \mathrm{C}$ showed the high TPA values. The best values for PR and PA were also obtained with $85 \%$ ACT, $300 \mu \mathrm{L} \mathrm{min}^{-1}$ and $80{ }^{\circ} \mathrm{C}$, being that range values below $85 \%$ ACT and $80{ }^{\circ} \mathrm{C}$ demonstrated a large drop in PR values and an increase in PA values. The range values of column flow rate only showed slight differences on the PR and PA response.

The DA was performed by overlay of CMAs responses to establish the optimal range values of CMPs and obtain the highest desirability index, and consequently, define the MODR. The desirability values for TPA, PR, and PA were based on the optimum, medium and poor response results, being defined as: desirable $(392,2.2$, and 1.0), acceptable (237, 1.8, and 1.1), and unacceptable (127, 1.4, and 1.2), respectively. The desirability analysis plots for interactions between CMPs, namely the ACT content vs column flow rate, ACT content vs column temperature, and column flow rate vs column temperature, are presented in Fig. 3 a, b, and c, respectively.

As expected, the highest desirability index was obtained in a region close to optimum conditions point, where the CMPs values were $85 \%$ of ACT, $300 \mu \mathrm{L} \mathrm{min}^{-1}$ of column flow rate and $80{ }^{\circ} \mathrm{C}$ of column temperature, being that the region of interaction around the optimum point was defined as the MODR of analytical method. The data verification of MODR was based on the analysis of agreement between the predicted and observed values at optimum point, being described in Online Resource 6. The results from data verification analysis demonstrated small differences between the observed and predicted values in CMA responses. However, the value of difference between the observed and predicted values was always close to $1 \%$. The observed differences may be due to the fact that the predicted values were calculated by the response of CMAs based only in three levels of CMPs that cover a wide range. Consequently, slight variations on intermediate precision at the optimum point can promote a visible
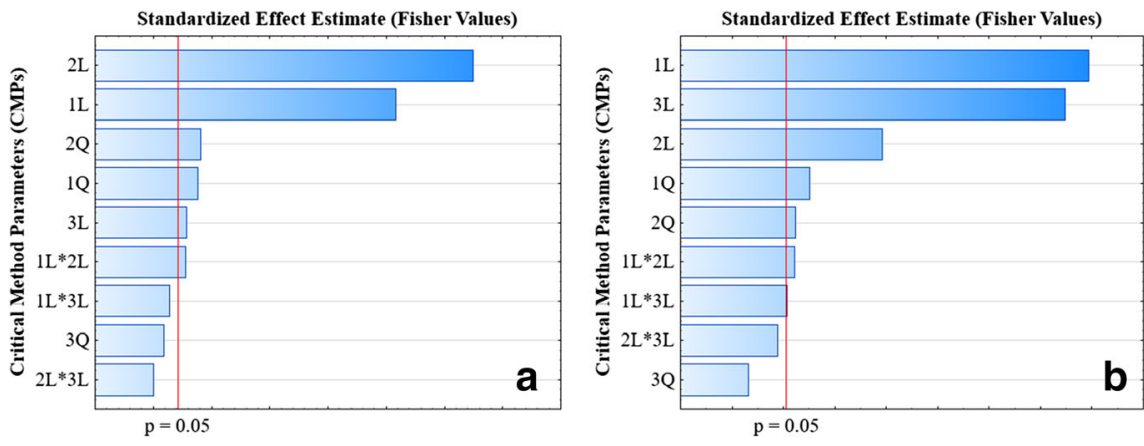

model and (Q) quadratic function model. Numbers correspond to (1) ACT content, (2) column flow, and (3) column temperature

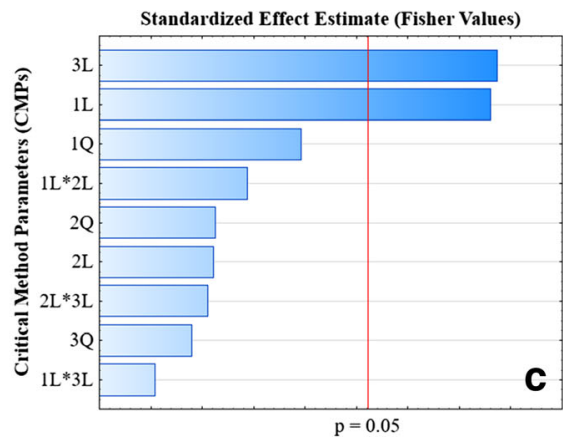

Fig. 1 Pareto chart plot of standardized effects of CMPs for definition of MODR regarding the total peak area (a), peak resolution (b), and peak asymmetry (c) results. Abbreviations correspond to (L) linear function 
a
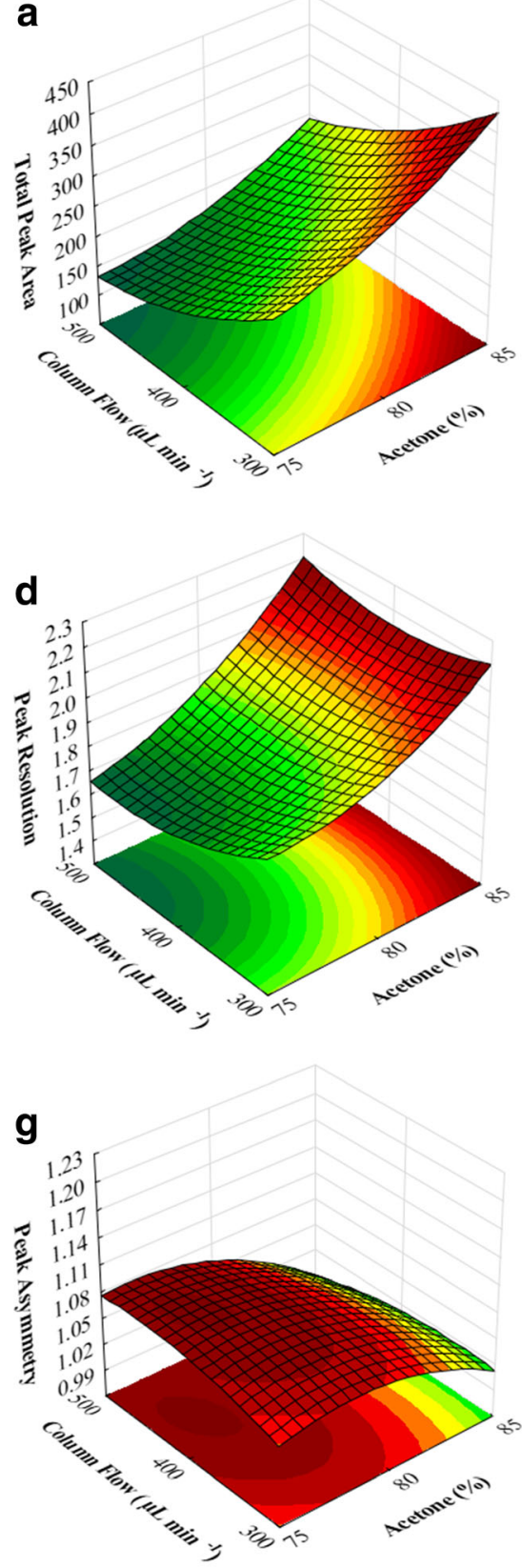

b


h

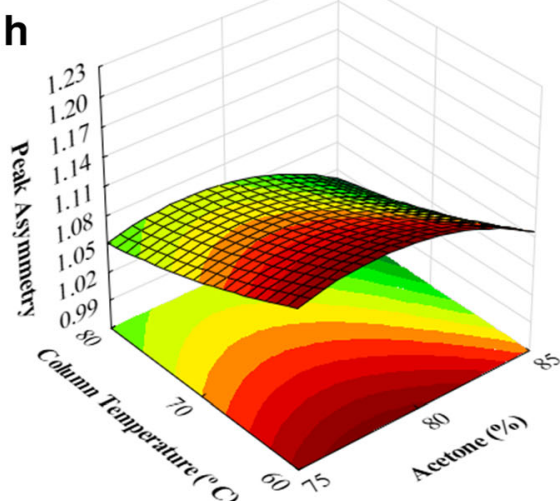

C
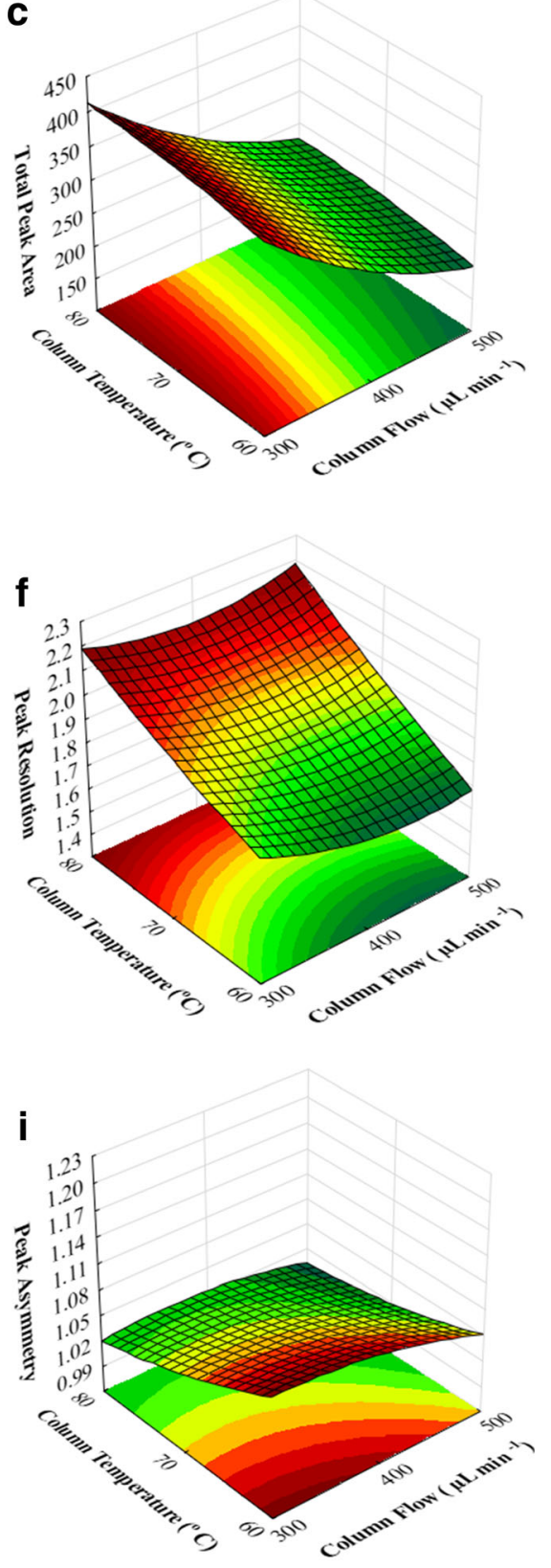

Fig. 2 Response surface methodology plot of interactions between the continuous CMPs, ACT content vs column flow, ACT content vs column temperature, and column flow vs column temperature, for definition of
MODR regarding the total peak area $(\mathbf{a}, \mathbf{b}$, and $\mathbf{c})$, peak resolution $(\mathbf{d}, \mathbf{e}$, and $\mathbf{f}$ ), and peak asymmetry (g, h, and i) results, respectively variability in the CMAs responses. For this reason, the MODR was evaluated by the analysis of the robustness at CMPs levels more closed to the optimal point, providing a rigorous and strict control of analytical method.

\section{Robustness and Method Control}

The control strategy of an analytical method performance during routine applications was based on evaluation of robustness, being normally achieve through the introduction of small and deliberate variations on the optimum conditions to verify if the analytical performance to remain unaffected. The evaluation of robustness was based on a new design of experiments performed at the optimum point into MODR. A fractional factorial design based on $3^{3}$-level factors model was performed for robustness screening, where were evaluated the ACT content $(84,85$, and $86 \%)$, column flow $(290,300$, and $\left.310 \mu \mathrm{L} \mathrm{min}{ }^{-1}\right)$, and column temperature $\left(79,80\right.$, and $\left.81{ }^{\circ} \mathrm{C}\right)$. 

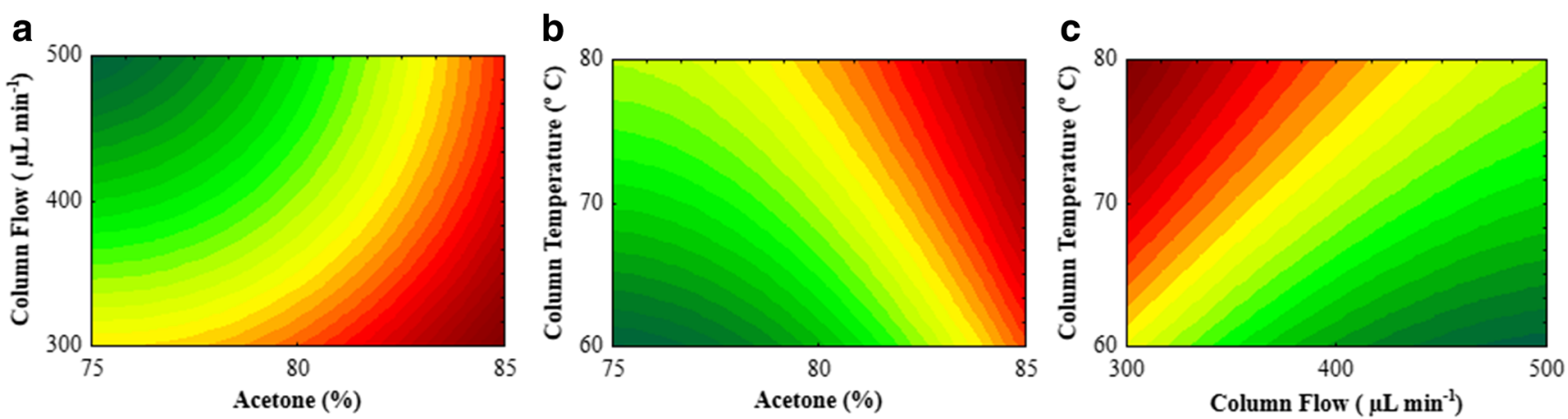

Fig. 3 Desirability analysis index plot of interactions between the continuous CMPs, ACT content vs column flow (a), ACT content vs column temperature (b), and column flow vs column temperature (c), for definition of MODR

The TPA, PR, and PA responses, CMPs, and respective range values for robustness screening model are summarized in Online Resource 7, 8 and 9, respectively.

The DA was performed on results obtained from robustness screening model. The selection of desirability values was based on RSD from TPA, PR, and PA responses at optimum point, being defined $0 \%$ as desirable, $0.5 \%$ as acceptable, and $1.0 \%$ as unacceptable. The DA plots for interactions between CMPs, namely the ACT content vs column flow, ACT content vs column temperature, and column flow vs column temperature, are presented in Fig. 4 a, b, and c, respectively.

The highest desirability index was verified with an ACT content between 85 and $86 \%$, a column flow between 290 and $300 \mu \mathrm{L} \min ^{-1}$, and a column temperature between 80 and $81{ }^{\circ} \mathrm{C}$, being that all RSD values were below of $0.1 \%$. The data verification of robustness screening results was completed by the agreement analysis between the predicted and observed values at optimal point. The results from data verification are summarized in Online Resource 10. The difference between observed values and predicted values is very low, being that $100 \%$ of observed values for all CMAs were within the $95 \%$ confidence interval, demonstrating a high robustness level at MODR optimal point.

The method control was based on establishment of system suitability limits by generating large amount of data (100 cases) through the Monte Carlo bootstrapping simulation at CMP optimal point into MODR, followed by application of capability analysis for estimation of residual errors from CMAs responses. The capability analysis for TPA, PR and PA are presented in Fig. 4 d, e, and f, respectively.

Most of cases (99\%) from Monte Carlo bootstrapping simulation for TPA remained between the lower specification
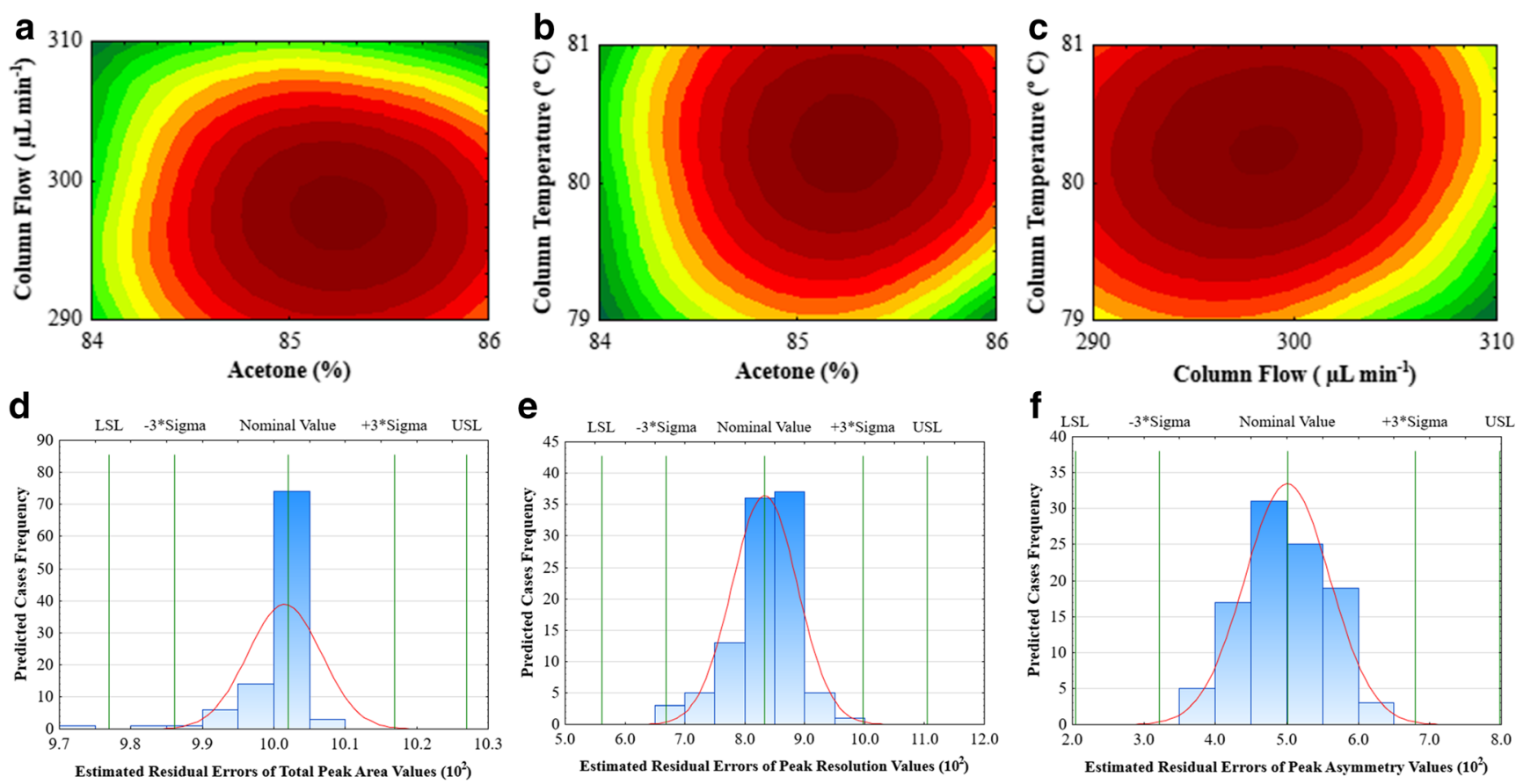

Fig. 4 Desirability analysis index plot of interactions between the continuous CMPs, ACT content vs column flow (a), ACT content vs column temperature (b), and column flow vs column temperature (c),

for evaluation of robustness at optimum point into MODR according. Capability analysis plot regarding the total peak area (d), peak resolution (e), and peak asymmetry (f) residual error results 
limit (0.098) and upper specification limit (0.103) established for residual error values $(\mathrm{RSD}<0.1 \%)$. The process capability index (Cpk) for TPA was 2.01. For PR and PA response simulation, all cases $(100 \%)$ were within the lower specification limit (0.056 and 0.020) and upper specification limit (0.083 and 0.080 ), where Cpk values were 1.70 and 1.60 , respectively. The reference value of $\mathrm{Cpk}$ is 1.33 , being the minimum value for a method to be considered robust (Tol et al. 2016). Thus, based on the obtained results from robustness screening and method control analysis at optimum point into MODR, our method demonstrated to have an exceptional robustness and prediction capacity.

\section{Validation of the Analytical Method}

The analytical method was validated for the following parameters: selectivity, calibration function, linearity, accuracy, precision, matrix effect, LOD, and LOQ, being performed according to guidelines from IUPAC (Thompson et al. 2002), and based on validation procedures established in our previous studies (Silva et al. 2017a, 2017b).

Selectivity evaluation was based on the analysis of chromatogram quality, namely the peak shape, resolution, RT, and the absence of interferences. The RTs are presented in Table 2. The chromatograms, (A) $\mathrm{SCH}$ sample spiked with sugars standards and (B) SCH sample, obtained at optimum conditions are presented in Fig. 5. The chromatograms showed that all sugars were clearly separated into a 20 -min run time, and the peaks shape were a well-defined Gaussian. Moreover, our analytical method also demonstrated to have a high selectivity when applied to real SCH samples, where PR values of identified sugars were 3.0 (GLU), 4.2 (FRU), and 3.3 (SUC).

Calibration functions of GLU, FRU, SUC, XYL, and MAN were performed by construction of the standard calibration curves prepared with six concentrations levels, being plotted as TPA vs concentration level. For each calibration curve, the function model and correlation coefficient were determined. The linearity of calibration functions was verified by the suitability analysis of each function model through determination of Fisher variance ( $F$ test), where if the ratio $F_{\text {theoretical }} / F_{\text {experimental }}$ value is higher than 1.0, the function model is suitable to describe the observed data without significant lack of fit. The results are summarized in Table 2.

Two different function models, linear and polynomial, were proposed and tested to validate the suitability of calibration curve for each sugar under analysis. The correlation coefficients of calibration curves for all sugars presented values above 0.99 in linear and polynomial function models. However, the $F$ test results demonstrated that the linear function model was not suitable $\left(F_{\text {theo }} / F_{\text {exp }}<1\right)$ for all sugars. Instead, the $F$ test results confirmed that the polynomial function model was suitable to describe the TPA response vs concentration level for all sugars, where the values of ratio $F_{\text {theo }} / F_{\text {exp }}$ were always higher than 1 .
The evaluation of accuracy, precision, matrix effect, LOD, and LOQ was based on the described polynomial function models. The results are summarized in Table 3.

The accuracy was achieved by determination of recovery rate (\%), being obtained by the ratio between the theoretical concentration value added to sample with experimental concentration values in a SCH sample spiked at low, medium, and high concentrations levels of each sugar. The analytical method proved to be strongly accurate at high-level concentrations. The recovery rates ranged between 98.2 (FRU) and 103.3\% (MAN), wherein all recovery values at high-level concentrations remained within the recommended limits from literature guidelines (95-105\%) (Gustavo González and Ángeles Herrador 2007). However, the accuracy was slightly inferior at medium and low-level concentrations, where some recovery values were above the recommended limits. These values may be due to the fact that the IR detector presents some noise at the chromatograms baseline. The precision was determined by repeatability and intermediate precision values, and were obtained through the inter- and intraday performance tests, respectively. The intraday variation was analyzed by evaluating ten replicates on the same day and inter-day variation by four replicates for each day during 3 days. The precision results were expressed as \% RSD. The precision of analytical method was very satisfactory, the repeatability values ranged between $3.8(\mathrm{GLU})$ and 6.4\% (XYL) and the intermediate precision values varied from 2.1 (SUC) to $6.1 \%$ (FRU), where all obtained values were below the maximum reference value (RSD $<10 \%$ ) (Gustavo González and Ángeles Herrador 2007). The matrix effect was determined by standard additions method, where the slopes from calibration curves of each sugar in $\mathrm{H}_{2} \mathrm{O}$ :ACT solution and $\mathrm{SCH}$ sample were compared at same concentration levels. The appearance of significant differences between the slopes was statically evaluated by Student $t$ test. The matrix effect results ranged between 91.76 (SUC) and $101.24 \%$ (MAN), wherein no significant differences were verified between slopes values from calibration curves, confirming that the matrix effect of analytical method was not significant. The LOD and LOQ were determinate based on standard deviations of interception and slope values from calibration curves performed in triplicate for each sugar, being calculated by following equations: $\mathrm{LOD}=3.3 \times$ $s$ slope $^{-1}$ and LOD $=10 \times s$ slope $^{-1}$. The LOD and LOQ values obtained through our analytical method were: 2.90 and $8.78 \mathrm{~g} \mathrm{~kg}^{-1}$ for GLU, 2.51 and $7.60 \mathrm{~g} \mathrm{~kg}^{-1}$ for FRU, 1.02 and $3.10 \mathrm{~g} \mathrm{~kg}^{-1}$ for SUC, 2.67 and $8.10 \mathrm{~g} \mathrm{~kg}^{-1}$ for XYL, and 3.24 and $9.81 \mathrm{~g} \mathrm{~kg}^{-1}$ for MAN, respectively. Comparing the LOD and LOQ values obtained for our analytical method with those described in the study performed by $\mathrm{Xu}$ and colleagues (Xu et al. 2015), where a method also based on LC-RI was developed for sugar analysis in sugarcane molasses samples, it was possible to confirm that the values obtained by our method are evidently lower to those 


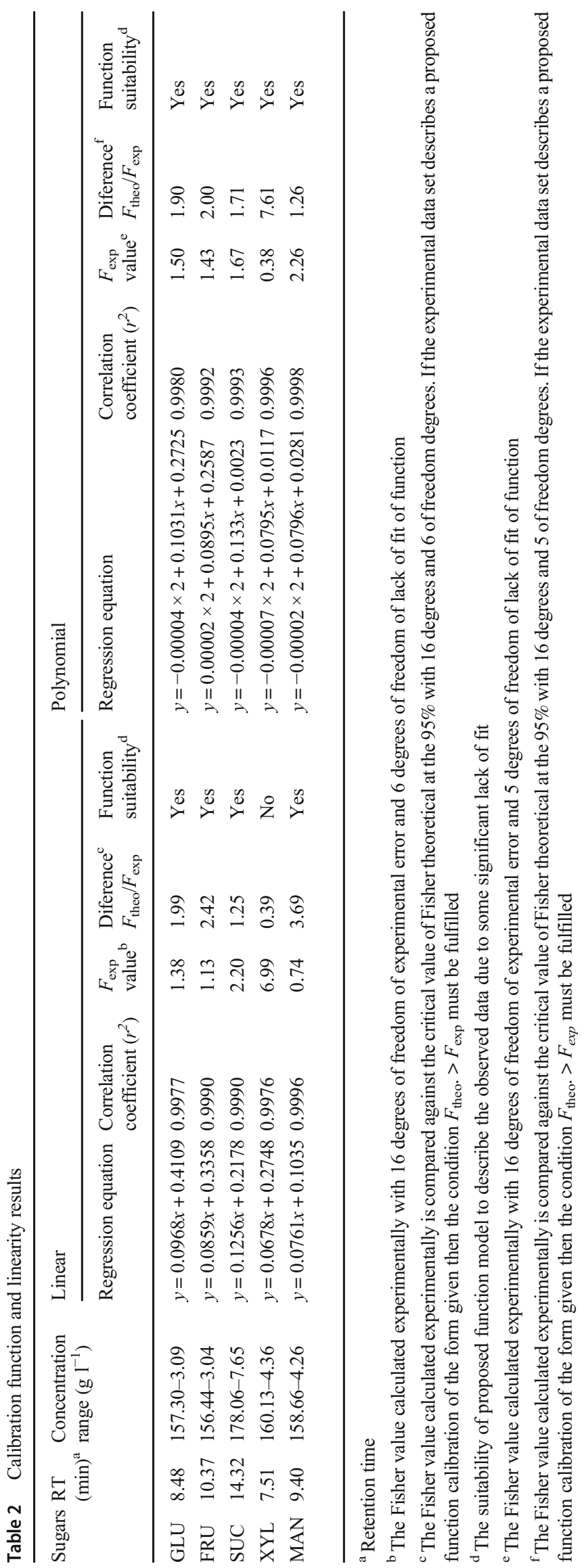


Fig. 5 Typical LC-RI chromatograms obtained for a sugarcane honey sample (a) and sugarcane honey sample spiked with sugar standards (b). Abbreviations bars correspond to (GLU) glucose, (FRU) fructose, (SUC) sucrose, (XYL) xylose, (MAN) mannose, and (RHA) rhamnose

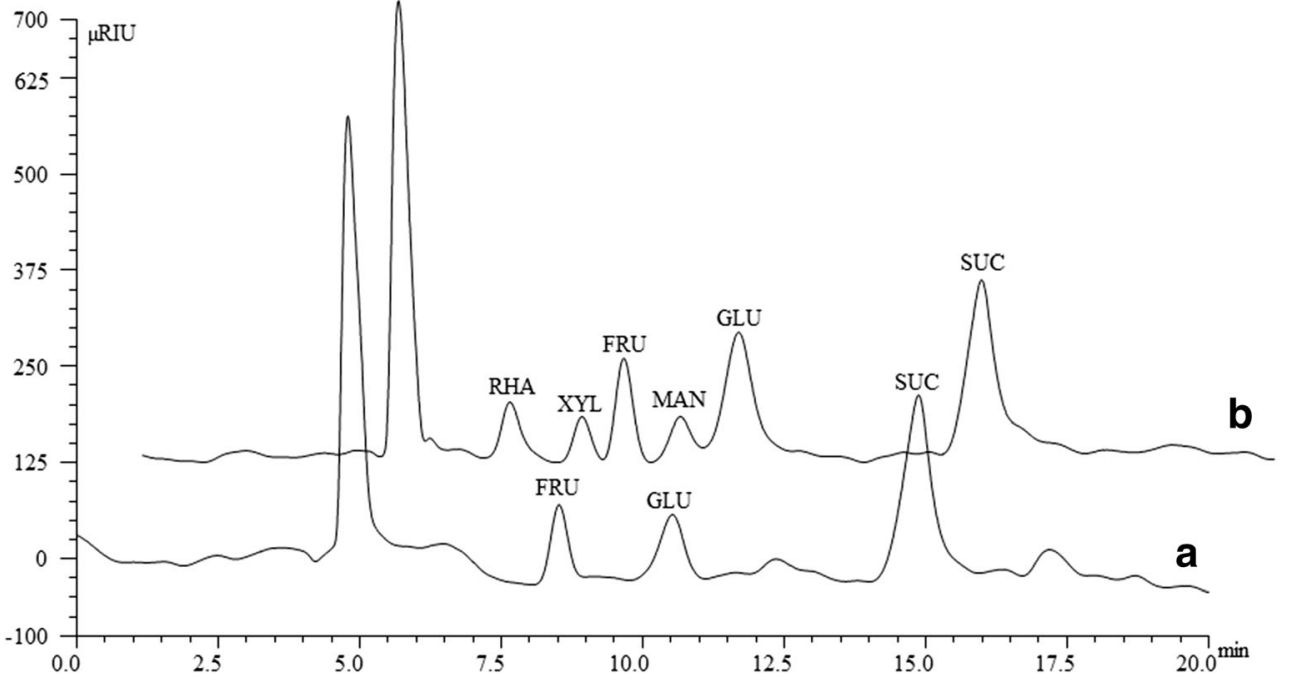

described in the study by Xu and colleagues (Xu et al. 2015), which presented LOD and LOQ values of 5.41 and $27.09 \mathrm{~g} \mathrm{~kg}^{-1}$ for GLU, 9.91 and $49.49 \mathrm{~g} \mathrm{~kg}^{-1}$ for FRU, and 17.84 and $89.19 \mathrm{~g} \mathrm{~kg}^{-1}$ for SUC, respectively.

\section{Method Application}

The applicability of USA-LLE/LC-RI analytical method was verified through the analysis of GLU, FRU, SUC, XYL, and
MAN in SCH samples from a certified producer obtained during three consecutive production years $(2016,2017$, and 2018). The results for the method applicability are summarized in Online Resource 11. The mean concentration values plot is presented in Fig. 6.

Based on the obtained results, it was possible to confirm the applicability of the developed analytical method on $\mathrm{SCH}$ real samples. Moreover, the results also demonstrated its high repeatability when applied in real $\mathrm{SCH}$ samples, where the

Table 3 Figures of merit of the method: accuracy, precision, matrix effect, LOD, and LOQ

\begin{tabular}{|c|c|c|c|c|c|c|c|c|c|}
\hline \multirow[t]{2}{*}{ Sugars } & \multirow{2}{*}{$\begin{array}{l}\text { Concentration } \\
\text { range }\left(\mathrm{g}^{-1}\right)\end{array}$} & \multicolumn{2}{|l|}{ Accuracy } & \multicolumn{2}{|l|}{ Precision } & \multicolumn{2}{|c|}{ Matrix effect } & \multirow{2}{*}{$\begin{array}{l}\mathrm{LOD} \\
\left(\mathrm{g} \mathrm{kg}^{-1}\right. \\
\left.\mathrm{SCH}^{-1}\right)\end{array}$} & \multirow{2}{*}{$\begin{array}{l}\text { LOQ } \\
\left(\mathrm{g} \mathrm{kg}^{-1}\right. \\
\left.\mathrm{SCH}^{-1}\right)\end{array}$} \\
\hline & & $\begin{array}{l}\text { Recovery } \\
(\%)\end{array}$ & $\begin{array}{l}\text { RSD } \\
(\%)\end{array}$ & $\begin{array}{l}\text { Repeatability } \\
\text { (\% RSD) }\end{array}$ & $\begin{array}{l}\text { Intermediate } \\
\text { precision (\% RSD) }\end{array}$ & $\begin{array}{l}\text { Variation } \\
\text { effect }(\%)\end{array}$ & $\begin{array}{l}\text { Significance }(p \\
\text { value }<0.05)\end{array}$ & & \\
\hline \multirow[t]{2}{*}{ GLU } & $\begin{array}{l}27.24^{\mathrm{a}} \\
11.28^{\mathrm{b}}\end{array}$ & $\begin{array}{l}101.4 \\
110.8\end{array}$ & $\begin{array}{l}2.8 \\
4.9\end{array}$ & $\begin{array}{l}3.8 \\
6.2\end{array}$ & $\begin{array}{l}3.4 \\
6.1\end{array}$ & \multirow[t]{2}{*}{92.94} & \multirow[t]{2}{*}{0.54} & \multirow[t]{2}{*}{2.90} & \multirow[t]{2}{*}{8.78} \\
\hline & $4.63^{\mathrm{c}}$ & 114.4 & 5.5 & 5.1 & 4.6 & & & & \\
\hline \multirow[t]{2}{*}{ FRU } & $\begin{array}{l}26.81 \\
11.10\end{array}$ & $\begin{array}{r}98.2 \\
108.4\end{array}$ & $\begin{array}{l}3.0 \\
4.5\end{array}$ & $\begin{array}{l}5.6 \\
6.1\end{array}$ & $\begin{array}{l}2.5 \\
6.1\end{array}$ & \multirow[t]{2}{*}{95.52} & \multirow[t]{2}{*}{0.55} & \multirow[t]{2}{*}{2.51} & \multirow[t]{2}{*}{7.60} \\
\hline & 4.56 & 114.7 & 1.5 & 5.9 & 4.8 & & & & \\
\hline \multirow[t]{2}{*}{ SUC } & $\begin{array}{l}67.36 \\
27.89\end{array}$ & $\begin{array}{r}99.9 \\
112.6\end{array}$ & $\begin{array}{l}4.1 \\
2.7\end{array}$ & $\begin{array}{l}4.1 \\
5.4\end{array}$ & $\begin{array}{l}2.1 \\
3.7\end{array}$ & \multirow[t]{2}{*}{91.76} & \multirow[t]{2}{*}{0.36} & \multirow[t]{2}{*}{1.02} & \multirow[t]{2}{*}{3.10} \\
\hline & 11.46 & 118.6 & 4.0 & 6.0 & 5.3 & & & & \\
\hline \multirow[t]{2}{*}{ XYL } & $\begin{array}{l}27.23 \\
11.01\end{array}$ & $\begin{array}{r}98.3 \\
115.5\end{array}$ & $\begin{array}{l}2.6 \\
1.2\end{array}$ & $\begin{array}{l}5.1 \\
6.4\end{array}$ & $\begin{array}{l}3.8 \\
3.7\end{array}$ & \multirow[t]{2}{*}{93.97} & \multirow[t]{2}{*}{0.09} & \multirow[t]{2}{*}{2.67} & \multirow[t]{2}{*}{8.10} \\
\hline & 4.35 & 119.5 & 6.0 & 5.9 & 5.2 & & & & \\
\hline \multirow[t]{2}{*}{ MAN } & $\begin{array}{l}26.62 \\
10.76\end{array}$ & $\begin{array}{l}103.3 \\
108.2\end{array}$ & $\begin{array}{l}1.2 \\
3.4\end{array}$ & $\begin{array}{l}4.8 \\
4.8\end{array}$ & $\begin{array}{l}2.8 \\
2.7\end{array}$ & \multirow[t]{2}{*}{101.24} & \multirow[t]{2}{*}{0.84} & \multirow[t]{2}{*}{3.24} & \multirow[t]{2}{*}{9.81} \\
\hline & 4.25 & 108.9 & 3.7 & 4.8 & 2.8 & & & & \\
\hline
\end{tabular}

The $p$ value calculated experimentally through ANOVA test between slopes obtained by calibration curves of sugars in SCH sample and solvent. If the obtained $p$ value was above that 0.05 , no significant matrix effect was observed

${ }^{\mathrm{c}}$ Low level concentration

${ }^{\mathrm{b}}$ Medium level concentration

${ }^{a}$ High level concentration 
Fig. 6 The mean concentration values $(n=3)$ of sugars obtained by USA-LLE/LC-RI analytical method for the sugarcane honey samples. Abbreviations bars correspond to (GLU) glucose, (FRU) fructose, (SUC) sucrose, (FRS16) certified sugarcane honey sample from 2016, (FRS16) certified sugarcane honey sample from 2017, and (FRS18) certified sugarcane honey sample from 2018

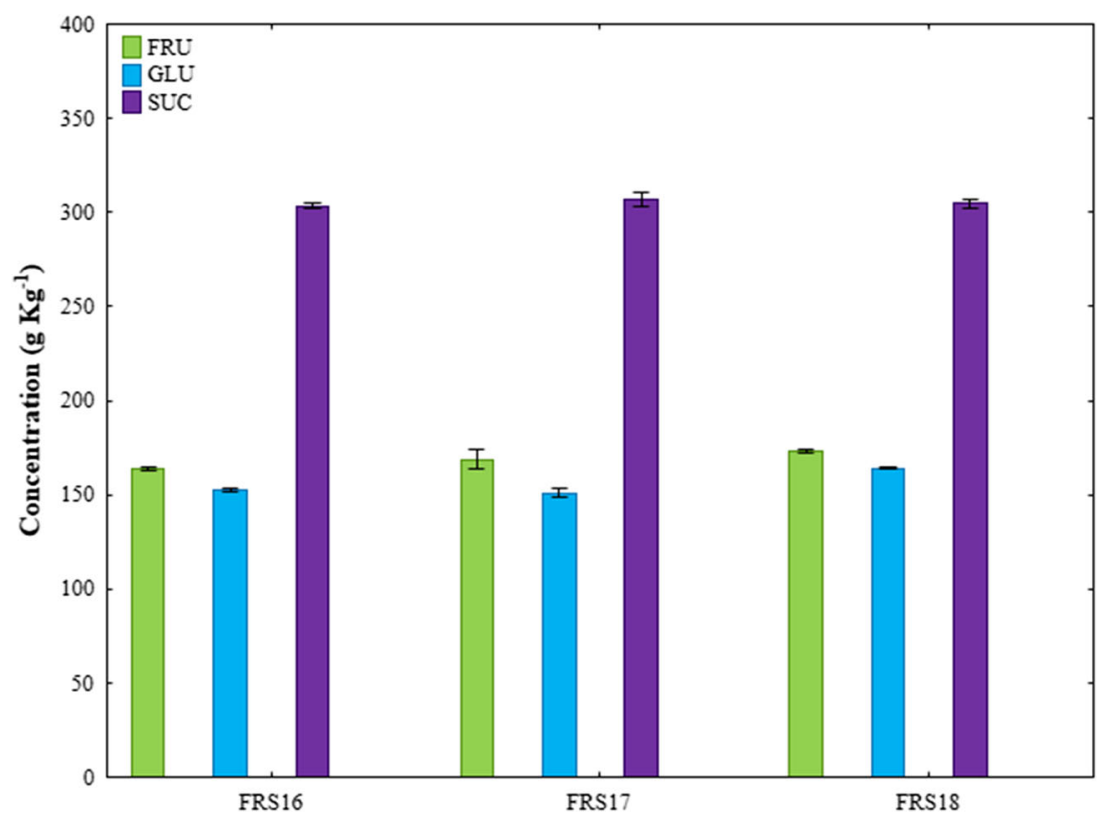

highest RSD value was $3.2 \%$, being that all concentrations values were obviously above the LODs and LOQs from the validation procedure.

Regarding the results from three $\mathrm{SCH}$ samples under analysis, only FRU, GLU, and SUC were identified and quantified in SCH samples under analysis, where the concentration values for FRU were $163.9 \mathrm{~g} \mathrm{~kg}^{-1}$ (2016), $168.9 \mathrm{~g} \mathrm{~kg}^{-1}$ (2017), and 173.4 $\mathrm{g} \mathrm{kg}^{-1}$ (2018); for GLU were $152.8 \mathrm{~g} \mathrm{~kg}^{-1}$ (2016), $151.1 \mathrm{~g} \mathrm{~kg}^{-1}$ (2017), and $164.0 \mathrm{~g} \mathrm{~kg}^{-1}$ (2018); and for SUC were $303.5 \mathrm{~g} \mathrm{~kg}^{-1}$ (2016), $307.0 \mathrm{~g} \mathrm{~kg}^{-1}$ (2017), and $304.7 \mathrm{~g} \mathrm{~kg}^{-1}$ (2018). Apparently, and according to concentrations values of FRU, GLU, and SUC from samples of the three production years, the typical sugars ratio of $\mathrm{SCH}$ product was 1:1:2 (GLU:FRU:SUC).

\section{Conclusions}

A precise and robust USA-LLE/LC-RI analytical method was successfully developed according to AQbD approach for GLU, FRU, SUC, XYL, and MAN analysis in real SCH samples. According to results obtained from method scouting, the more efficient procedure for sugars extraction from SCH samples was based on LLE assisted by ultrasounds during $10 \mathrm{~min}$, with an extraction solution composed by $\mathrm{H}_{2} \mathrm{O}$ :ACT $\left(50: 50 \%, v v^{-1}\right)$ in a ratio sample/solution of 1:3 $\left(w v^{-1}\right)$. The MODR was based on chromatography performance, wherein its optimal conditions for LC-RI analysis was obtained with a BEH AMIDE column operating at a temperature of $80{ }^{\circ} \mathrm{C}$, flow rate of $300 \mu \mathrm{L} \mathrm{min}{ }^{-1}$ and an eluent composed by $\mathrm{H}_{2} \mathrm{O}$ :ACT $\left(15: 85 \%, v v^{-1}\right)$ in isocratic gradient mode. The method control procedure demonstrated through Monte Carlo simulation and capability analysis that the developed analytical method was highly robust at optimal point of MODR. The analytical method also proved through the validation procedures to be selective, accurate, precise, and without significant matrix effect, demonstrating lower LOD and LOQ values compared to other similar previous studies. The applicability of the method was confirmed with high repeatability by sugars analysis of real SCH samples provided by a certified producer during three consecutive production years (2016, 2017, and 2018), where only GLU, FRU and SUC were identified and quantified in typical ratio of $1: 1: 2$, respectively. In conclusion, it is possible to state that the application of USA-LLE/ LC-RI analytical method provide a simple, effective, precise and robust strategy for the establishment of typicity of genuine SCH product, being a useful and promising tool to guarantee its authenticity in a global market.

Acknowledgments This work was supported by FCT-Fundação para a Ciência e a Tecnologia through the CQM Base Fund - UIDB/00674/ 2020, and Programmatic Fund - UIDP/00674/2020, and by ARDITIAgência Regional para o Desenvolvimento da Investigação Tecnologia e Inovação, through the project M1420-01-0145-FEDER-000005 Centro de Química da Madeira - CQM+ (Madeira 14-20 Program) The authors acknowledge the Fábrica Mel-de-Cana Ribeiro Sêco de V. Melim, Lda, (FMCRS), Funchal, Portugal, and the Agência Regional para o Desenvolvimento da Investigação, Tecnologia e Inovação (ARDITI) through the support granted under the M1420 Project - 095369-FSE-000001 - PhD Scholarship in companies for PhD grant of the author Pedro Silva.

Conceptualization Pedro Silva, Fernando Nunes, and José S. Câmara; Methodology: Pedro Silva, Catarina L. Silva and Rosa Perestrelo; Formal analysis and investigation: Pedro Silva; Writing - original draft preparation: Pedro Silva; Writing - review and editing: Pedro Silva, Catarina L. Silva, Rosa Perestrelo, Fernando Nunes and José S. Câmara; Funding acquisition: José S. Câmara; Resources: José S. Câmara; Supervision: Fernando Nunes and José S. Câmara. 
Author Contributions All authors contributed to the study conception and design. Material preparation, data collection and analysis were performed by Pedro Silva, Catarina L. Silva and Rosa Perestrelo. The first draft of the manuscript was written by Pedro Silva, and all authors commented on previous versions of the manuscript. All authors read and approved the final manuscript.

\section{Compliance with Ethical Standards}

Competing Interests The authors declare that they have no conflict of interest.

Ethical Approval This article does not contain any studies with human participants or animals performed by any of the authors.

Informed Consent Informed consent is not applicable to this study.

\section{References}

Al Eid SM (2006) Chromatographic separation of fructose from date syrup. Int J Food Sci Nutr 57:83-96. https://doi.org/10.1080/ 09637480600658286

Ancillotti C, Orlandini S, Ciofi L, Pasquini B, Caprini C, Droandi C, Furlanetto S, del Bubba M (2018) Quality by design compliant strategy for the development of a liquid chromatography-tandem mass spectrometry method for the determination of selected polyphenols in Diospyros kaki. J Chromatogr A 1569:79-90. https://doi. org/10.1016/J.CHROMA.2018.07.046

Anjos O, Campos MG, Ruiz PC, Antunes P (2015) Application of FTIRATR spectroscopy to the quantification of sugar in honey. Food Chem 169:218-223. https://doi.org/10.1016/J.FOODCHEM.2014. 07.138

Bai W, Fang X, Zhao W, Huang S, Zhang H, Qian M (2015) Determination of oligosaccharides and monosaccharides in Hakka rice wine by precolumn derivation high-performance liquid chromatography. J Food Drug Anal 23:645-651. https://doi.org/10.1016/J. JFDA.2015.04.011

Balli D, Bellumori M, Orlandini S, Cecchi L, Mani E, Pieraccini G, Mulinacci N, Innocenti M (2020) Optimized hydrolytic methods by response surface methodology to accurately estimate the phenols in cereal by HPLC-DAD: the case of millet. Food Chem 303: 125393. https://doi.org/10.1016/j.foodchem.2019.125393

Başar B, Özdemir D (2018) Determination of honey adulteration with beet sugar and corn syrup using infrared spectroscopy and geneticalgorithm-based multivariate calibration. J Sci Food Agric 98:56165624. https://doi.org/10.1002/jsfa.9105

Benvenuti ME, Burgess J (2012) Determination of food sugars in fruit juice using refractive index detection and $\mathrm{BEH}$ amide column chemistry

Borman P, Nethercote P, Chatfield M, Thompson D (2007) The application of quality by design to analytical methods. Pharm Technol 31:142-152

Cantín CM, Gogorcena Y, Moreno MÁ (2009) Analysis of phenotypic variation of sugar profile in different peach and nectarine [ Prunus persica (L.) Batsch] breeding progenies. J Sci Food Agric 89:1909 1917. https://doi.org/10.1002/jsfa.3672

Chávez-servín JL, Castellote AI, López-Sabater MC (2004) Analysis of mono- and disaccharides in milk-based formulae by highperformance liquid chromatography with refractive index detection. J Chromatogr A 1043:211-215. https://doi.org/10.1016/J. CHROMA.2004.06.002

Coelho EM, da Silva Padilha CV, Miskinis GA, de Sá AGB, Pereira GE, de Azevêdo LC, dos Santos Lima M (2018) Simultaneous analysis of sugars and organic acids in wine and grape juices by HPLC: method validation and characterization of products from northeast Brazil. J Food Compos Anal 66:160-167. https://doi.org/10.1016/J. JFCA.2017.12.017

Cordella C, Militão JSLT, Clément M-C, Drajnudel P, Cabrol-Bass D (2005) Detection and quantification of honey adulteration via direct incorporation of sugar syrups or bee-feeding: preliminary study using high-performance anion exchange chromatography with pulsed amperometric detection (HPAEC-PAD) and chemometrics. Anal Chim Acta 531:239-248. https://doi.org/10.1016/J.ACA. 2004.10.018

European Medicines Agency (EMA) and Food and Drug Administration (FDA) (2013) EMA-FDA pilot program for parallel assessment of Quality-by-Design applications: lessons learnt and Q\&amp;A resulting from the first parallel assessment

Filip M, Vlassa M, Coman V, Halmagyi A (2016) Simultaneous determination of glucose, fructose, sucrose and sorbitol in the leaf and fruit peel of different apple cultivars by the HPLC-RI optimized method. Food Chem 199:653-659. https://doi.org/10.1016/j. foodchem.2015.12.060

Georgelis N, Fencil K, Richael CM (2018) Validation of a rapid and sensitive HPLC/MS method for measuring sucrose, fructose and glucose in plant tissues. Food Chem 262:191-198. https://doi.org/ 10.1016/J.FOODCHEM.2018.04.05

Ghfar AA, Wabaidur SM, Ahmed AYBH, Alothman ZA, Khan MR, alShaalan NH (2015) Simultaneous determination of monosaccharides and oligosaccharides in dates using liquid chromatographyelectrospray ionization mass spectrometry. Food Chem 176:487492. https://doi.org/10.1016/J.FOODCHEM.2014.12.035

Grembecka M, Lebiedzińska A, Szefer P (2014) Simultaneous separation and determination of erythritol, xylitol, sorbitol, mannitol, maltitol, fructose, glucose, sucrose and maltose in food products by high performance liquid chromatography coupled to charged aerosol detector. Microchem J 117:77-82. https://doi.org/10.1016/J. MICROC.2014.06.012

Guadalupe Z, Martínez-Pinilla O, Garrido Á, Carrillo JD, Ayestarán B (2012) Quantitative determination of wine polysaccharides by gas chromatography-mass spectrometry (GC-MS) and size exclusion chromatography (SEC). Food Chem 131:367-374. https://doi.org/ 10.1016/J.FOODCHEM.2011.08.049

Gustavo González A, Ángeles Herrador M (2007) A practical guide to analytical method validation, including measurement uncertainty and accuracy profiles. TrAC - Trends Anal Chem 26:227-238. https://doi.org/10.1016/j.trac.2007.01.009

Hanna-Brown, Melissa Borman PJ, Bale S, Szucs R et al (2010) Development of chromatographic methods using QbD principles. Sep Sci 2:12-20

Hu X, Shi Y, Zhang P et al (2016) D-mannose: properties, production, and applications: an overview. Compr. Rev. food Sci. Food Saf 15: 773-785

Idda I, Spano N, Ciulu M, Nurchi VM, Panzanelli A, Pilo MI, Sanna G (2016) Gas chromatography analysis of major free mono- and disaccharides in milk: method assessment, validation, and application to real samples. J Sep Sci 39:4577-4584. https://doi.org/10.1002/ jssc. 201600583

International Conference on Harmonisation (ICH) (2009) The International Conference on Harmonisation tripartite guideline. Pharmaceutical development Q8 (R2). Int Conf Harmon Tech Requir Regist Pharm Hum Use

Jamróz MK, Paradowska K, Zawada K, Makarova K, Kaźmierski S, Wawer I (2014a) 1H and 13C NMR-based sugar profiling with chemometric analysis and antioxidant activity of herbhoneys and honeys. J Sci Food Agric 94:246-255. https://doi.org/10.1002/jsfa. 6241

Jamróz MK, Paradowska K, Zawada K, Makarova K, Kaźmierski S, Wawer I (2014b) ${ }^{1} \mathrm{H}$ and ${ }^{13} \mathrm{C}$ NMR-based sugar profiling with chemometric analysis and antioxidant activity of herbhoneys and 
honeys. J Sci Food Agric 94:246-255. https://doi.org/10.1002/jsfa. 6241

Karabagias IK (2019) Seeking of reliable markers related to Greek nectar honey geographical and botanical origin identification based on sugar profile by HPLC-RI and electro-chemical parameters using multivariate statistics. Eur Food Res Technol:1-12. https://doi.org/ 10.1007/s00217-018-3216-Z

Kek SP, Chin NL, Tan SW, Yusof YA, Chua LS (2017) Classification of honey from its bee origin via chemical profiles and mineral content. Food Anal Methods 10:19-30. https://doi.org/10.1007/s12161-0160544-0

Koh D, Park J, Lim J, Yea MJ, Bang DY (2018) A rapid method for simultaneous quantification of 13 sugars and sugar alcohols in food products by UPLC-ELSD. Food Chem 240:694-700. https://doi. org/10.1016/J.FOODCHEM.2017.07.142

Lindqvist DN, Pedersen HÆ, Rasmussen LH (2018) A novel technique for determination of the fructose, glucose and sucrose distribution in nectar from orchids by HPLC-ELSD. J Chromatogr B 1081-1082: 126-130. https://doi.org/10.1016/J.JCHROMB.2018.02.019

Ma C, Sun Z, Chen C, Zhang L, Zhu S (2014) Simultaneous separation and determination of fructose, sorbitol, glucose and sucrose in fruits by HPLC-ELSD. Food Chem 145:784-788. https://doi.org/10. 1016/J.FOODCHEM.2013.08.135

Magwaza LS, Opara UL (2015) Analytical methods for determination of sugars and sweetness of horticultural products - a review. Sci Hortic (Amsterdam) 184:179-192. https://doi.org/10.1016/J.SCIENTA. 2015.01.001

Mellado-Mojica E, Seeram NP, López MG (2016) Comparative analysis of maple syrups and natural sweeteners: carbohydrates composition and classification (differentiation) by HPAEC-PAD and FTIR spectroscopy-chemometrics. J Food Compos Anal 52:1-8. https://doi. $\operatorname{org} / 10.1016 /$ j.jfca.2016.07.001

Molnár I, Rieger H-J, Monks KE (2010) Aspects of the "design space" in high pressure liquid chromatography method development. J Chromatogr A 1217:3193-3200. https://doi.org/10.1016/j.chroma. 2010.02 .001

Muñiz-Márquez DB, Contreras JC, Rodríguez R, Mussatto SI, Wong-Paz JE, Teixeira JA, Aguilar CN (2015) Influence of thermal effect on sugars composition of Mexican Agave syrup. CyTA - J Food 13:16. https://doi.org/10.1080/19476337.2015.1028452

Ni C, Zhu B, Wang N, Wang M, Chen S, Zhang J, Zhu Y (2016) Simple column-switching ion chromatography method for determining eight monosaccharides and oligosaccharides in honeydew and nectar. Food Chem 194:555-560. https://doi.org/10.1016/J. FOODCHEM.2015.08.049

Nikolaou C, Karabagias IK, Gatzias I, Kontakos S, Badeka A, Kontominas MG (2017) Differentiation of fresh Greek Orange juice of the Merlin cultivar according to geographical origin based on the combination of organic acid and sugar content as well as physicochemical parameters using chemometrics. Food Anal Methods 10: 2217-2228. https://doi.org/10.1007/s12161-016-0757-2

Özbalci B, Boyaci İH, Topcu A, Kadılar C, Tamer U (2013) Rapid analysis of sugars in honey by processing Raman spectrum using chemometric methods and artificial neural networks. Food Chem 136: 1444-1452. https://doi.org/10.1016/J.FOODCHEM.2012.09.064

Rakete S, Glomb MA (2013) A novel approach for the quantitation of carbohydrates in mash, wort, and beer with RP-HPLC using 1naphthylamine for precolumn derivatization. J Agric Food Chem 61:3828-3833. https://doi.org/10.1021/jf400463r

Rodríguez-Sánchez S, Hernández-Hernández O, Ruiz-Matute AI, Sanz ML (2011) A derivatization procedure for the simultaneous analysis of iminosugars and other low molecular weight carbohydrates by GC-MS in mulberry (Morus sp.). Food Chem 126:353-359. https:// doi.org/10.1016/J.FOODCHEM.2010.10.097
Rovio S, Sirén K, Sirén H (2011) Application of capillary electrophoresis to determine metal cations, anions, organic acids, and carbohydrates in some Pinot Noir red wines. Food Chem 124:1194-1200. https:// doi.org/10.1016/J.FOODCHEM.2010.07.044

Saska M, Ozer E (1995) Aqueous extraction of sugarcane bagasse hemicellulose and production of xylose syrup. Biotechnol Bioeng 45: 517-523. https://doi.org/10.1002/bit.260450609

Seguí L, Calabuig-Jiménez L, Betoret N, Fito P (2015) Physicochemical and antioxidant properties of non-refined sugarcane alternatives to white sugar. Int J Food Sci Technol 50:2579-2588. https://doi.org/ $10.1111 /$ ijfs. 12926

de FG da Silva M, Dionísio AP, de Abreu FAP et al (2018) Evaluation of nutritional and chemical composition of yacon syrup using $1 \mathrm{H}$ NMR and UPLC-ESI-Q-TOF-MSE. Food Chem 245:1239-1247. https://doi.org/10.1016/J.FOODCHEM.2017.11.092

Silva P, Freitas J, Silva CL, Perestrelo R, Nunes FM, Câmara JS (2017a) Establishment of authenticity and typicality of sugarcane honey based on volatile profile and multivariate analysis. Food Control 73:1176-1188. https://doi.org/10.1016/j.foodcont.2016.10.035

Silva P, Silva CL, Perestrelo R et al (2018) Fingerprint targeted compounds in authenticity of sugarcane honey - an approach based on chromatographic and statistical data. LWT 96:82-89. https://doi. org/10.1016/J.LWT.2018.04.076

Silva P, Silva CL, Perestrelo R, Nunes FM, Câmara JS (2017b) A useful strategy based on chromatographic data combined with quality-bydesign approach for food analysis applications. The case study of furanic derivatives in sugarcane honey J Chromatogr A 1520:117126. https://doi.org/10.1016/J.CHROMA.2017.09.019

Terol A, Paredes E, Maestre SE, Prats S, Todolí JL (2010) Hightemperature liquid chromatography inductively coupled plasma atomic emission spectrometry hyphenation for the combined organic and inorganic analysis of foodstuffs. J Chromatogr A 1217:61956202. https://doi.org/10.1016/J.CHROMA.2010.07.083

Thompson M, Ellison SLR, Wood R (2002) Harmonized guidelines for single-laboratory validation of methods of analysis (IUPAC technical report). Pure Appl Chem 74:835-855. https://doi.org/10.1351/ pac200274050835

Tol T, Kadam N, Raotole N, Desai A, Samanta G (2016) A simultaneous determination of related substances by high performance liquid chromatography in a drug product using quality by design approach. J Chromatogr A 1432:26-38. https://doi.org/10.1016/j.chroma. 2015.12.080

Vaccari G, Lodi G, Tamburini E, Bernardi T, Tosi S (2001) Detection of oligosaccharides in sugar products using planar chromatography. Food Chem 74:99-110. https://doi.org/10.1016/S0308-8146(01) 00137-6

Wang S, Guo Q, Wang L, Lin L, Shi H, Cao H, Cao B (2015) Detection of honey adulteration with starch syrup by high performance liquid chromatography. Food Chem 172:669-674. https://doi.org/10. 1016/J.FOODCHEM.2014.09.044

Wang T, Yang X, Wang D, Jiao Y, Wang Y, Zhao Y (2012) Analysis of compositional carbohydrates in polysaccharides and foods by capillary zone electrophoresis. Carbohydr Polym 88:754-762. https:// doi.org/10.1016/J.CARBPOL.2012.01.039

Willems JL, Low NH (2012) Major carbohydrate, polyol, and oligosaccharide profiles of agave syrup. Application of this data to authenticity analysis. J Agric Food Chem 60:8745-8754. doi: https://doi. org/10.1021/jf3027342

Xu W, Liang L, Zhu M (2015) Determination of sugars in molasses by HPLC following solid-phase extraction. Int J Food Prop 18:547557. https://doi.org/10.1080/10942912.2013.837064

Publisher's Note Springer Nature remains neutral with regard to jurisdictional claims in published maps and institutional affiliations. 